\title{
De novo designed receptor transmembrane domains enhance CAR-T cell cytotoxicity and attenuate cytokine release
}

Assaf Elazar ${ }^{1,{ }^{*}}$, Nicholas J. Chandler ${ }^{2,4,}{ }^{,}$, Ashleigh S. Davey ${ }^{2,4,}{ }^{*}$, Jonathan Y. Weinstein ${ }^{1}$, Julie V. Nguyen ${ }^{2}$, Raphael Trenker ${ }^{2,4}$, Misty R. Jenkins ${ }^{3,4,5}$, Melissa J. Call ${ }^{2,4, \#}$, Matthew E. Call ${ }^{2,4, \#}$ and Sarel J. Fleishman $^{1, \#}$

1. Department of Biomolecular Sciences, Weizmann Institute of Science, Rehovot, Israel.

2. Structural Biology Division, The Walter and Eliza Hall Institute of Medical Research, Parkville, Victoria 3052, Australia

3. Immunology Division, The Walter and Eliza Hall Institute of Medical Research, Parkville, Victoria 3052, Australia

4. Department of Medical Biology, The University of Melbourne, Parkville, Victoria 3052, Australia

5. La Trobe Institute of Molecular Science, La Trobe University, Bundoora, Victoria 3083, Australia

${ }^{*}$ Equal first authors

"Equal senior and corresponding authors

\begin{abstract}
De novo designed receptor transmembrane domains (TMDs) present opportunities for precise control of cellular functions. We develop a strategy for generating programmed membrane proteins (proMPs): single-pass $\alpha$-helical TMDs that form oligomeric complexes through computationally defined and crystallographically validated interfaces. To demonstrate their usefulness, we program specific oligomeric interactions into a chimeric antigen receptor (to generate proCARs) and analyze the cytotoxic potency and cytokine release profiles of proCAR-T cells. We show that dimeric and trimeric proCAR-expressing $T$ cells have significantly enhanced antitumor cytotoxicity compared to a monomeric proCAR and a reference CAR similar to those currently used in the clinic. Independently of oligomeric state, all proCAR-T cells exhibited strongly attenuated inflammatory cytokine release. These results have important implications for both safety and efficacy of cellular immunotherapies and highlight the advantages of programming precise structural features in engineered receptors through de novo protein design. The proMPs provide an exceptionally modular route to tuning receptor function and can be easily incorporated into existing CAR designs.
\end{abstract}


bioRxiv preprint doi: https://doi.org/10.1101/2020.07.26.221598; this version posted July 26,2020 . The copyright holder for this preprint (which was not certified by peer review) is the author/funder, who has granted bioRxiv a license to display the preprint in perpetuity. It is made available under aCC-BY-NC-ND 4.0 International license.

\section{Introduction}

Interactions among cell-surface receptors play central roles in determining complex receptor structures and controlling signal propagation. In immune receptors (Berry and Call, 2017; Dong et al., 2019), death receptors (Fu et al., 2016; Pan et al., 2019) and growth factor receptors (Arkhipov et al., 2013; Endres et al., 2013; Fleishman et al., 2002), for example, the transmembrane domains (TMDs) govern key interactions involved in assembly, activation and higher-order clustering. Control over the specificity, stability, geometry and oligomeric state of these interactions is therefore highly desirable both for mechanistic studies of natural receptors and in the engineering of synthetic receptors. Such control, however, is difficult to achieve using natural TMDs that have likely been evolutionarily selected for a degree of flexibility in these very attributes (Matthews et al., 2006). The importance of high precision in receptor engineering has come into particularly sharp focus with the recent FDA approval of the first cellular immunotherapies for cancer using chimeric antigen receptors (CARs) (Eshhar et al., 1993; June et al., 2018; Majzner and Mackall, 2019; Salter et al., 2018), single-chain hybrid sensors that endow patient T cells with cytotoxic antitumor activity.

The modular domain organization of CARs offers significant scope to incorporate highly customized sequences that exert control over their structure and function. Current-generation CARs comprise an antibody single-chain variable fragment domain for tumor antigen binding; a spacer or hinge domain for length and flexibility; a TMD controlling membrane integration and potentially self-association; and intracellular costimulation and activation domains that provide signals for proliferation, survival and activation of T cell effector functions. Efforts to imbue CARs with optimal signaling properties have probed all of these domains in one way or another (Alabanza et al., 2017; Balakrishnan et al., 2019; James, 2018; Liu et al., 2015; Mata and Gottschalk, 2019; Rafiq et al., 2020). The TMDs, however, have received little attention in systematic studies of CAR design. For convenience, most CARs incorporate the TMD sequence of the same protein from which the adjacent hinge or signalling domains were derived; that is, most commonly from endogenous T cell proteins such as $\mathrm{CD} 4, \mathrm{CD} 8 \alpha, \mathrm{CD} 28$ or the T cell receptor (TCR)-associated $\zeta$ chain. At least some of these TMD sequences can engage in molecular interactions that drive self-association and/or assembly with the essential T cell proteins from which they were derived (Bridgeman et al., 2010, 2014; Call et al., 2002, 2006; Hennecke and Cosson, 1993; Leddon et al., 2020) and thereby impact CAR surface expression and functional properties in ways that reduce control over signalling outcomes. The $\zeta$ TMD, for example, drives 
bioRxiv preprint doi: https://doi.org/10.1101/2020.07.26.221598; this version posted July 26,2020 . The copyright holder for this preprint (which was not certified by peer review) is the author/funder, who has granted bioRxiv a license to display the preprint in perpetuity. It is made available under aCC-BY-NC-ND 4.0 International license.

both self-association (to form homodimers) and incorporation into endogenous TCR-CD3 complexes in the T-cell membrane (Call et al., 2002, 2006; Cosson et al., 1991; Dong et al., 2019; Rutledge et al., 1992). The sequence determinants of these homotypic and heterotypic interactions are overlapping (Call et al., 2006) and therefore difficult to disentangle, and yet both appear to exert significant control over CAR signalling (Bridgeman et al., 2010, 2014). The hinge and TMD sequences used in current FDA-approved CAR-T cell therapies derive from either CD8 $\alpha$ or CD28; although experimentally less well characterised, these sequences carry similar risks of confounding interactions with endogenous T cell signalling proteins (Fujiwara et al., 2020; Hennecke and Cosson, 1993; Leddon et al., 2020), thus hampering the rational design of CARs with predictable properties.

Recent studies have shown that the strength and quality of CAR activating signals can indeed be strongly modulated by the choice of hinge and TMD sequences. For example, the human CD28 hinge-TMD sequence has been associated with stronger activating signals and higher sensitivity to low-antigen tumors compared with the human CD8 $\alpha$ hinge-TMD sequence (Alabanza et al., 2017; Brudno et al., 2020; Fujiwara et al., 2020; Majzner et al., 2020). The CD28 sequence, however, also confers higher cytokine toxicity and reduced CAR-T cell survival, which are typically undesirable outcomes. While the detailed findings in these studies necessarily vary due to design differences, they all confirm some or all of these associations even when antigen-binding, costimulatory and activation domains are held constant. The underlying mechanisms that may explain these associations are yet unknown and they have not been attributed specifically to the hinge or TMD. Still, possible roles for the hinge and TMD may include driving CAR self-association into high-order structures, associations with endogenous signaling proteins (including, for instance, the endogenous CD28) or controlling cell-surface expression and stability.

We set out to define the relationships between TMD structure and signalling in CAR-T cells by designing completely new TMDs with high levels of membrane integration, programmable self-association features and minimal risk of cross-talk with native T-cell components. Despite significant recent progress (Barth and Senes, 2016; Korendovych and DeGrado, 2020), the limitations of membrane-protein (MP) atomistic calculations have restricted de novo MP design studies to highly predictable and rigid coiled-coil motifs (Joh et al., 2014; Lu et al., 2018) that, while stabilising them, limited their usefulness as receptor TMDs. By contrast, we recently described an ab initio Rosetta atomistic modelling strategy (Weinstein et al., 2019) which uses a 
new energy function with experimentally determined membrane-solvation terms for each amino acid to accurately predict the structure of single-spanning sequences known to self-assemble (Elazar et al., 2016a, 2016b). Here we introduce a new strategy to de novo design proMPs (programmable Membrane Proteins) resulting in completely new sequences that form TM homo-oligomers of defined geometry and order and can be used to program cell-surface receptor structure. We used structure-validated proMPs to generate proCAR constructs and found that these endowed T cells with superior cytotoxicity and lower inflammatory cytokine release compared to otherwise identical CARs containing natural TMDs. These results shed new light on the importance of precision in engineered receptor structure and intermolecular associations for optimal CAR-T activity.

\section{Results}


a

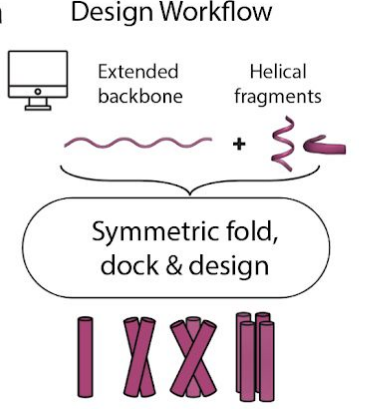

b

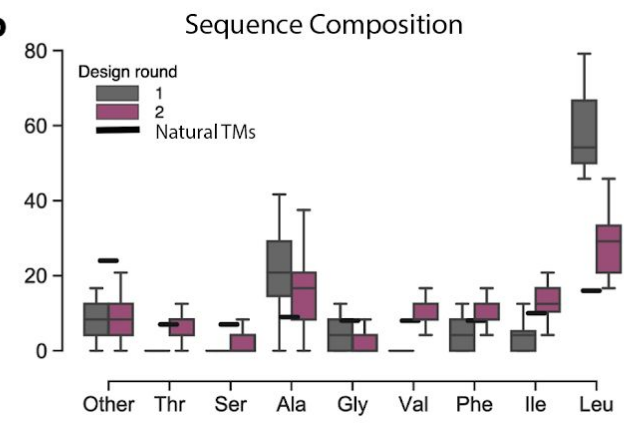

C Self-Association in E. coli - Designs $=$ ErbB2 $=$ QSOX2 $-\mathrm{CLS}$

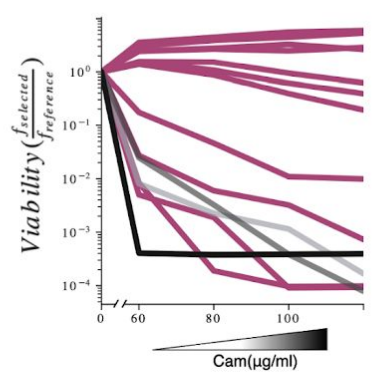

f

FLSLVGALIGAFIAFILALFILV

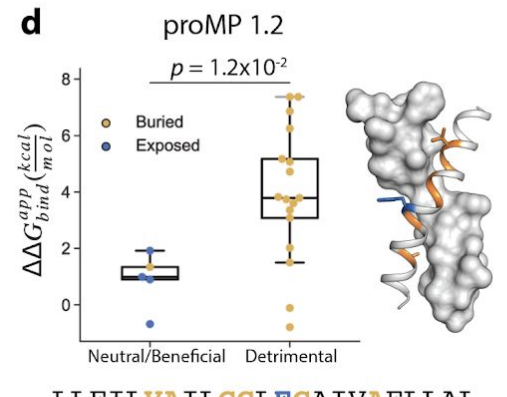

e
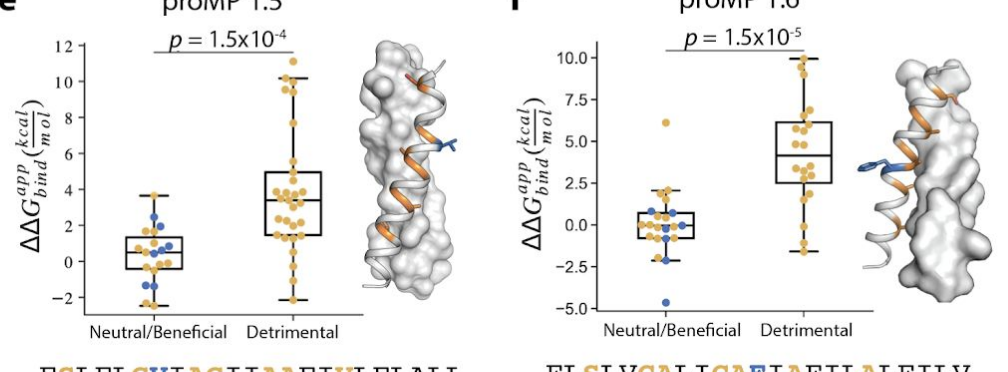

FSLFLGVIAGIIAAFIVLFLALL

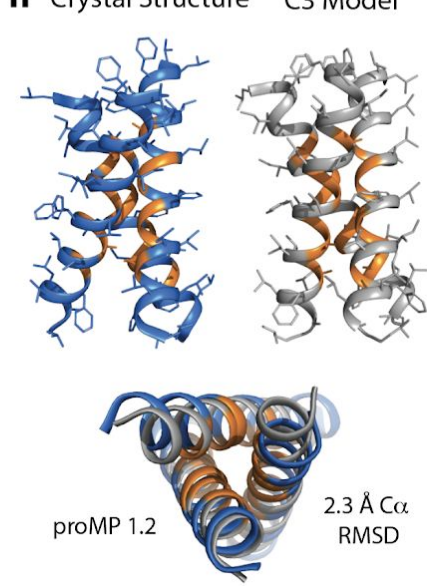

proMP 1.2 structure prediction calculations in C3 symmetry

i

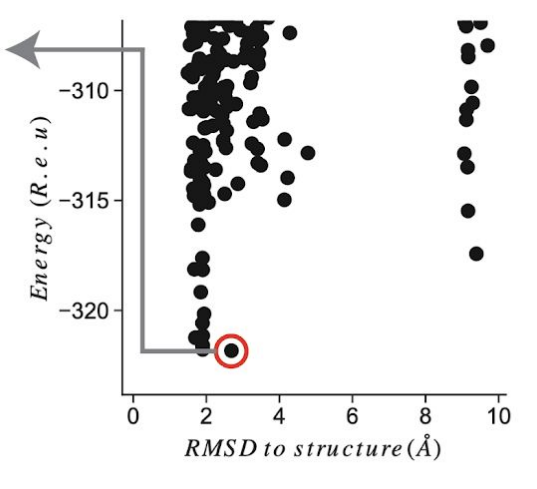

Figure 1: Learning the rules for programming self-associating MPs. (a) Rosetta fold, dock and design uses backbone fragments from natural MPs to construct symmetric, de novo architectures and a membrane-protein energy function (Weinstein et al., 2019) to optimise the amino acid sequence. (b) Round 1 designs were biased towards the hydrophobic amino acid Leu relative to naturally occurring TMDs. In round 2, we incorporated a sequence diversification step which conformed the amino acid propensities to those observed in natural TMDs. (c) The proMPs strongly self-associate in the $E$. coli inner membrane as evidenced by high viability in the T $\beta$ L self-association assay (Elazar et al., 2016a). (d-f) Designed positions that are buried at the interface (orange) are more sensitive to mutation according to deep sequencing $\mathrm{T} \beta \mathrm{L}$ analysis (Elazar et al., 2016a) ( $y$-axis) than exposed positions (blue). Mutations are predicted to be detrimental or neutral/beneficial using computational mutation scanning of the model structures (Methods). (g) proMPs produced as free peptides form heat-stable homo-oligomers in detergent. SDS-PAGE samples containing 15,45 and $135 \mu \mathrm{g}$ of peptide were heated to $95^{\circ} \mathrm{C}$ for 1 minute and run under reducing conditions. $\left({ }^{*}\right)$ Indicates the position of a minor contaminant from the fusion protein used to generate 
bioRxiv preprint doi: https://doi.org/10.1101/2020.07.26.221598; this version posted July 26, 2020. The copyright holder for this preprint (which was not certified by peer review) is the author/funder, who has granted bioRxiv a license to display the preprint in perpetuity. It is made available under aCC-BY-NC-ND 4.0 International license.

proMP peptides (Methods). Molecular weight below each gel is for a monomer of the corresponding peptide sequence with additional N-terminal EPE and C-terminal RRLC flanking sequences (Methods). See additional examples in Supplemental Data Figure 3. (h, i) The $2.55 \AA$ A resolution structure (blue ribbon) determined from crystals grown in monoolein lipid cubic phase (LCP) shows that proMP 1.2, designed to form a dimer, associates to form a trimer in a lipid bilayer environment. (i) Forward-folding $a b$ initio prediction of proMP 1.2 in trimeric (C3) symmetry results in a model structure ( $h$, gray ribbon) that is very close to the experimentally determined one.

\section{Atomically precise de novo designed TMDs}

In our initial design approach (Figure 1a), each computational trajectory started from two fully symmetric and extended chains of 24 amino acids encoding either poly-Val or poly-Ala (supplemental Movie). In a first, coarse-grained modelling step, backbone torsion angles were sampled from a database comprising 3 and 9 amino acid fragments from $\alpha$-helical MPs, and the two chains were symmetrically docked against one another with an energy term that disfavoured large crossing angles (Eq. 1) (Bowie, 1997; Weinstein et al., 2019). In a second, all-atom step, we refined the sequence and the structure through iterations of symmetric sequence optimisation, backbone minimisation, and rigid-body docking using the ref2015_memb atomistic energy function that is dominated by van der Waals packing, hydrogen bonding and amino acid lipophilicity. We noticed that the resulting sequences were overwhelmingly biased towards the large and flexible hydrophobic amino acid Leu (Figure 1b), as expected from the dominant role of lipophilicity in the ref2015_memb potential (Weinstein et al., 2019). Forward-folding ab initio structure-prediction calculations, however, indicated that the designs were prone to form multiple alternative low-energy dimers instead of the designed ones (Supplemental Data Figure 1a). To mitigate the risk of misfolding due to the high Leu content, we introduced a sequence diversification step comprising 120 iterations of single-point mutations and energy relaxation while biasing the sequence composition to match that of natural TMDs (Figure 1b; Eq. 2-3). The resulting sequences were subjected to $a b$ initio structure prediction calculations (Das et al., 2009) and this time, they converged to the design models (Supplemental Data Figure 1b) and exhibited a large energy gap from undesired structures. It was noted that natural TMDs are not optimised for thermodynamic stability (Faham et al., 2004); interestingly, our results suggest that evolution may have selected sequence compositions to counter TMD misfolding. 
Twelve designs were tested in the E. coli TOXCAT- $\beta$-lactamase (T $\beta \mathrm{L}$ ) selection system (Elazar et al., 2016a; Langosch et al., 1996). In this dual-reporter system, survival on ampicillin and chloramphenicol reports on a design's membrane-insertion and self-association propensity, respectively (Supplemental Data Figure 2). Remarkably, most proMPs supported high survival (Figure 1c) and two-thirds survived even at the highest chloramphenicol concentration tested, indicating a self-association strength significantly greater than the TMD from ErbB2, which served as a positive control. The patterns of sensitivity to interface mutations of most designs were also consistent with the design models (Figure 1d-f and Supplemental Data Figure 3), suggesting that they indeed assembled through the designed interfaces in the bacterial inner membrane. Eight proMPs were produced recombinantly as free TM peptides and all exhibited electrophoretic mobility consistent with SDS- and heat-stable self-association (Figure 19 and Supplemental Data Figure 3). The patterns of migration, however, were not uniform. Six proMPs had the apparent molecular weight of a dimer (e.g., proMP 1.5 and 1.6, Figure $\mathbf{1 g}$ ) and exhibited reduced mobility as the peptide concentration was increased, similar to the SDS-stable (Lemmon et al., 1992) behaviour of the well-studied glycophorin A TMD (Supplemental Data Figure 3). By contrast, the remaining two proMPs exhibited migration that was independent of the sample concentration and had apparent molecular weights more consistent with oligomers larger than the designed dimers (proMP 1.2, Figure 1g; proMP 1.3, Supplemental Data Figure 3). To establish the molecular structure of these designs, several were screened for crystallisation in monoolein lipid cubic phase, and the structure of proMP 1.2 was determined to $2.55 \AA$ resolution (Figure $\mathbf{1 h}$ and Supplemental Data Figure 4). While the positions involved in helix packing recapitulated the design model, this proMP indeed formed a trimer instead of the intended dimer. Ab initio structure prediction calculations in trimeric (C3) symmetry recapitulated the experimentally observed packing interface (RMSD $2.3 \AA$ A) (Figure $\mathbf{1 h}-\mathbf{i}$ ), demonstrating that it would have been possible to predict this outcome had we considered alternative oligomeric states. 
a

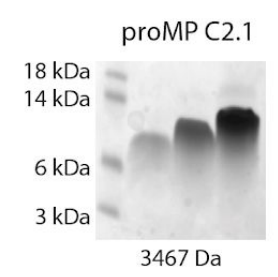

LTVALILGIFLGTFIAFWVVYLL

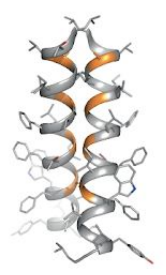

b

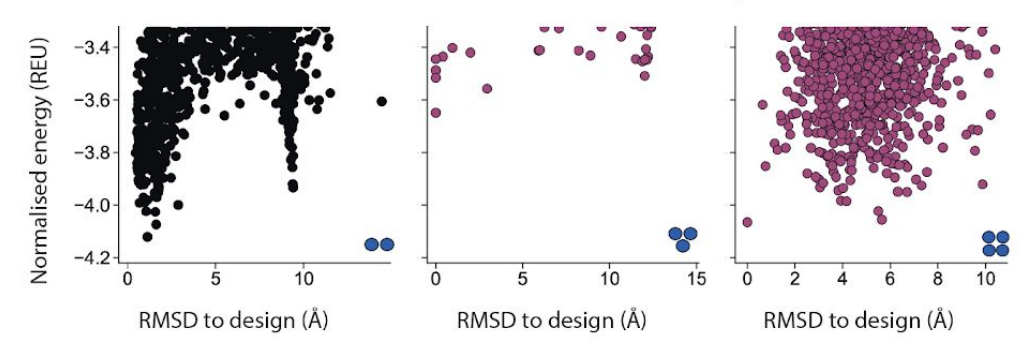

d Rosetta Calculations in C2/C3/C4 Symmetries
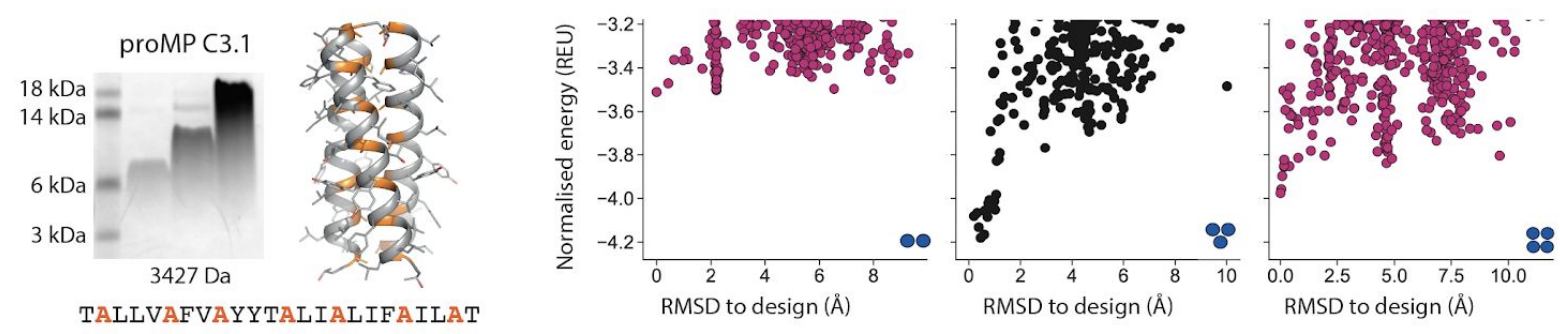

$\mathrm{h}$
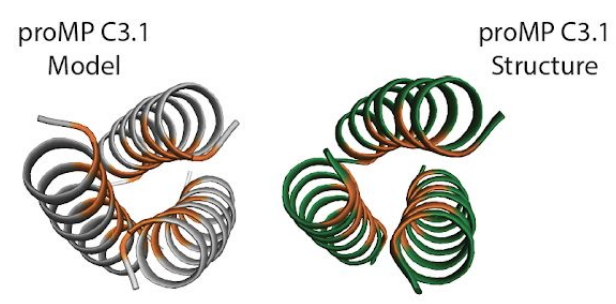

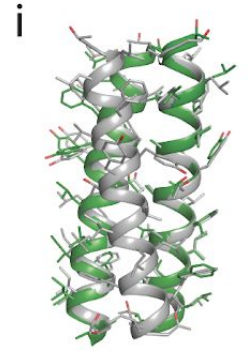

$0.4 \AA ̊$ C $\alpha$ RMSD (parallel helices)

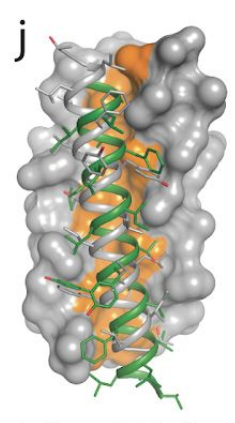

Antiparallel helices

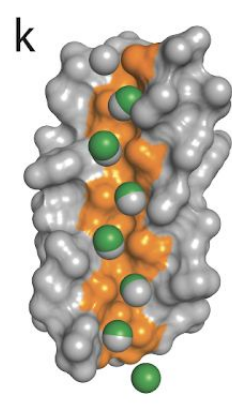

Ala $\beta$ methyls

Figure 2: Designed MPs of defined structure and oligomeric state. (a) Migration of proMP C2.1 is consistent with a dimer in gel-shift assays. Design model and peptide sequence shown for reference. (b) Rosetta $a b$ initio structure prediction calculations predict that proMP C2.1 preferentially forms a dimer. (c) proMP C3.1 exhibits a novel Ala-dominated interface, and its migration at high sample concentration suggests a complex larger than a dimer. Design model and peptide sequence shown for reference. (d) $a b$ initio calculations predict that it primarily forms a trimer. (e-g) the proMP C2.1 designed structure is atomically verified by a $2.7 \AA$ crystal structure. Interfacial positions are marked in orange. (h-k) the crystallographic analysis of proMP C3.1 (3.5 ^̊ resolution) reveals a trimer that is almost identical to the design, although one of the three helices in the trimer is antiparallel relative to the other two in the crystal lattice. Alignment of the structure and model (i) shows that the antiparallel helix (green) (j) positions Ala C $\beta$ methyls that pack into the trimer through the designed interface (grey) (k). 
Based on this insight, a third design campaign was initiated to produce proMPs in a range of oligomeric states, incorporating a final step in which ab initio structure prediction calculations (Weinstein et al., 2019) were performed in C2, C3 and C4 symmetries for every design. Only those proMPs that were predicted to form the target oligomeric state and none of the alternatives were selected for further analysis (Figure 2a-d). This strategy yielded two proMPs for which we obtained crystal structures confirming the target oligomeric state: a dimer with glycine-based packing interface similar to the motif observed in human glycophorin A (proMP C2.1; Figure 2a-b, e-g and Supplemental Data Figure 5), and a trimer with an alanine-rich interface which, to the best of our knowledge, is novel (proMP C3.1; Figure 2c-d, h-k and Supplemental Data Figure 6). Interestingly, while two of the helices in the crystal structure of proMP C3.1 aligned extremely well with the design model (Figure $\mathbf{2} \mathbf{i}$ ), the third was in an antiparallel orientation (Figure $\mathbf{2} \mathbf{j}$ ). Despite this arrangement, the six key interface alanine $\beta$-methyls were in near-identical positions to their counterparts in the fully parallel model (Figure $\mathbf{2 k}$ ) leading us to suspect that the model is correct but the crystal lattice was enforcing the antiparallel binding mode of the third helix. To probe this possibility, we aligned the parallel model with the asymmetric unit seen in the crystal structure and generated crystallographic symmetry, showing clashes for the third helix and indicating that the design model cannot be accommodated in the crystal lattice. The structure thus suggests that this proMP is unintentionally "reversible" in that one of the helices can form the intended packing mode in either orientation. While this feature is of great interest from a design standpoint (Woodall et al., 2015), we note that only the fully parallel trimer depicted in the model can form in a biological system where the topology of a single-spanning TMD is constrained by the biosynthetic machinery in a type-I orientation.

We conclude that the sequence diversification and the computational selection of oligomeric state described above provide a practical approach to implement essential negative-design principles in TMD design (Fleishman and Baker, 2012; Joh et al., 2014); this approach will likely also be critical to design de novo hetero-oligomeric TMDs.

ProCARs increase CAR-T cell cytotoxic potency while reducing inflammatory cytokine release 
a

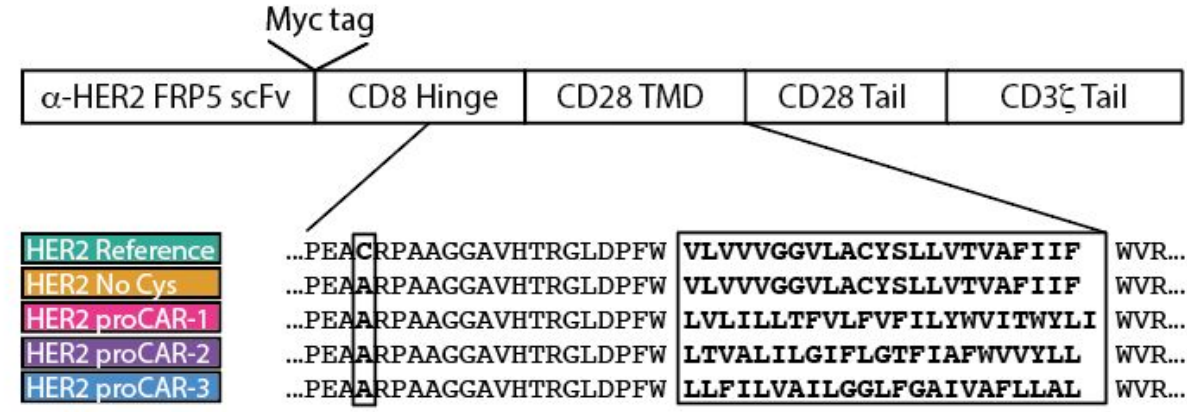

b Surface expression BW5147 cells

C Surface IP ( $\alpha$-lgG) - Western blot ( $\alpha$-myc)
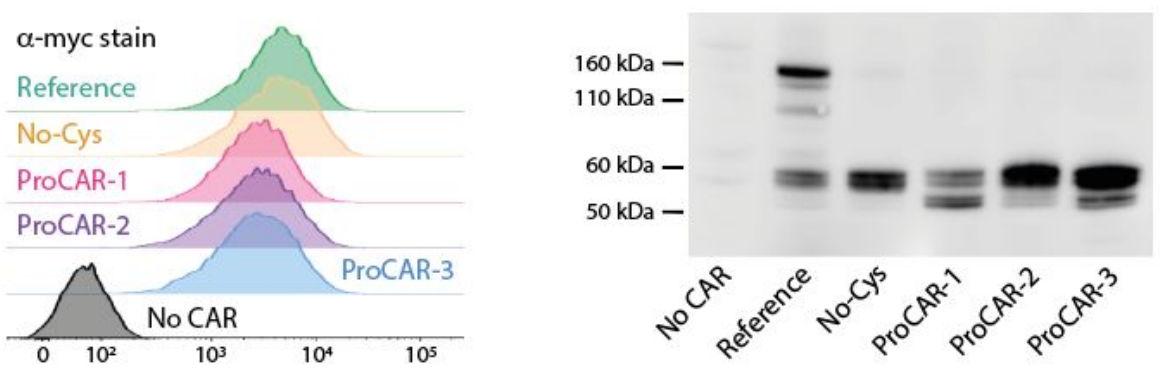

d CD69 upregulation in BW5147 cells

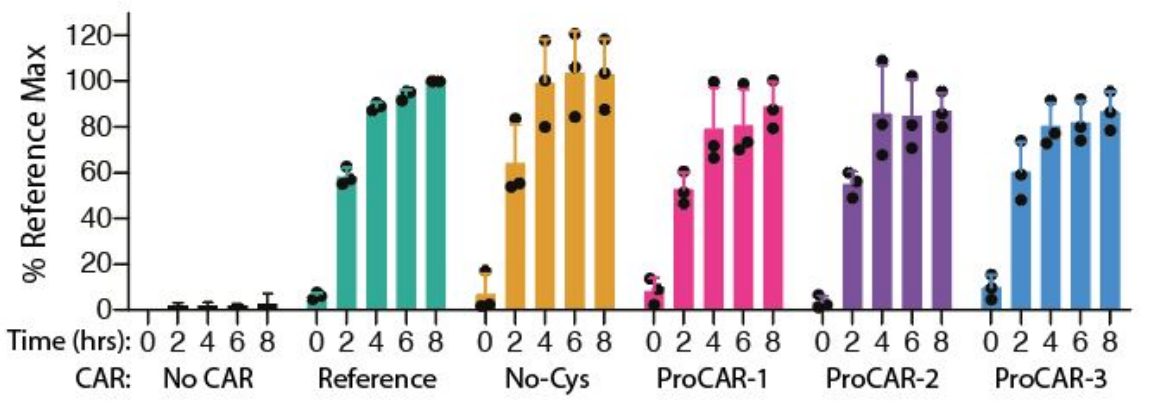

e $\quad \mathrm{NFkB}$ activation in BW5147 cells

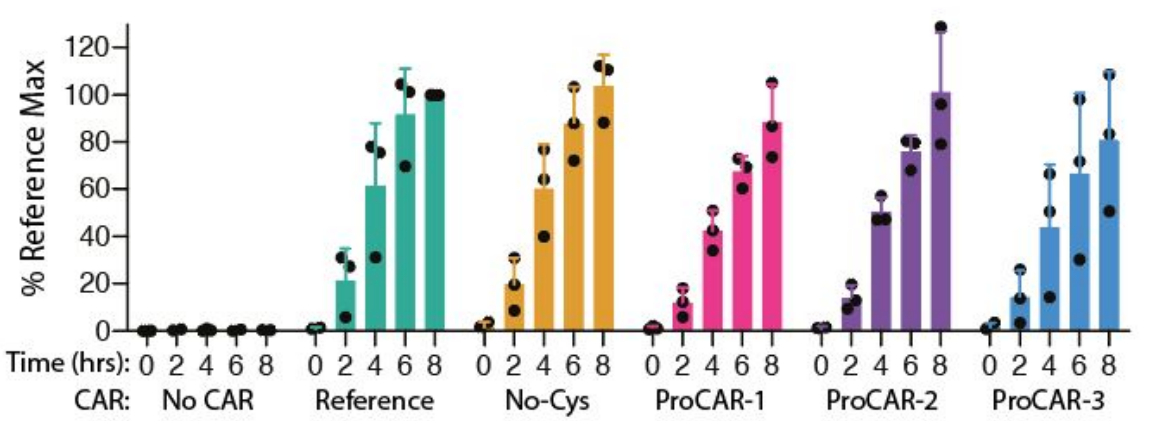

Figure 3: HER2-specific proCARs are expressed and functional. (a) Schematic showing the domain organisation of the reference HER2-specific CAR construct and modifications made to introduce proMP TMDs. Bold, boxed sequence indicates the human CD28 TMD in the reference/no cys CARs and designed proMP sequences in the monomeric (ProCAR-1), dimeric (ProCAR-2) and trimeric (ProCAR-3) receptors. (b) BW5147 murine thymoma cells stably expressing proCARs, reference CARs and a destabilised GFP NF-KB reporter were surface stained with anti-myc antibody and analysed by flow cytometry to assess surface expression levels. (c) Live cells from (b) were coated with polyclonal anti-lgG to bind CARs through the scFv domain and immunoprecipitated using protein $\mathrm{G}$ beads. Products were separated by non-reducing 
bioRxiv preprint doi: https://doi.org/10.1101/2020.07.26.221598; this version posted July 26,2020 . The copyright holder for this preprint (which was not certified by peer review) is the author/funder, who has granted bioRxiv a license to display the preprint in perpetuity. It is made available under aCC-BY-NC-ND 4.0 International license.

SDS-PAGE and immunoblotted using anti-myc antibody to visualise surface-expressed CAR proteins.

Molecular weight of the CAR polypeptide is $55 \mathrm{kDa}$. (d, e) Cells from (b) were co-cultured with HER2+ SKBR3 human breast adenocarcinoma cells for the indicated times and analysed by flow cytometry for upregulation of activation marker CD69 (d) and GFP expression from the NF-KB reporter (e). All activation levels are normalised to the 8-hr time point in cells expressing the reference CAR (\% Reference Max). Bars represent the mean and dots the individual data points for three independent experiments beginning with fresh retroviral transductions. Error bars indicate standard deviations.

The results of the de novo design campaign, $\mathrm{T} \beta \mathrm{L}$ selection and structural analysis provided validated proMPs that could be used to program chimeric receptors to form dimers or trimers, for which we chose the crystallographically confirmed proMPs C2.1 and 1.2 (proCAR-2 and proCAR-3, respectively; Figure 3). We also designed a highly expressed monomeric proMP that exhibited no chloramphenicol survival in dsT $\beta$ L assays (Supplemental Data Figure 7) and used it to produce the monomeric proCAR-1. As our background, we chose a well-studied second-generation HER2-specific CAR (Davenport et al., 2015; Haynes et al., 2002) that delivers potent cytotoxicity and cytokine release in vitro and in vivo. This CAR incorporates the HER2-binding FRP5 ScFv (Wels et al., 1992) affinity domain, a human CD8 $\alpha$ hinge, the human CD28 TM and costimulatory domains and the human $\mathrm{CD} 3 \zeta$-chain activation domain (Figure 3a). A cysteine residue in the CD8 $\alpha$ hinge mediates disulphide-bond formation that generates predominantly covalent dimers on the T cell surface. We mutated this cysteine to alanine to ensure that the designed TMDs were the only determinants of oligomeric state and replaced the 23-amino-acid human CD28 TMD with monomeric, dimeric or trimeric proMP sequences. The panel of HER2 proCARs was retrovirally expressed in murine BW5147 thymoma cells, where they all reached the cell surface (Figure 3b-c) and were competent to signal when co-cultured with HER2 ${ }^{+}$SKBR3 human breast adenocarcinoma cells (Figure 3d-e). A surface-capture and immunoblot analysis confirmed the reference CAR (Reference) formed disulphide-linked dimers, while the cysteine mutant (No Cys) and all proCARs migrated as monomers on non-reducing SDS-PAGE (Figure 3c). 
a Representative Killing Assay

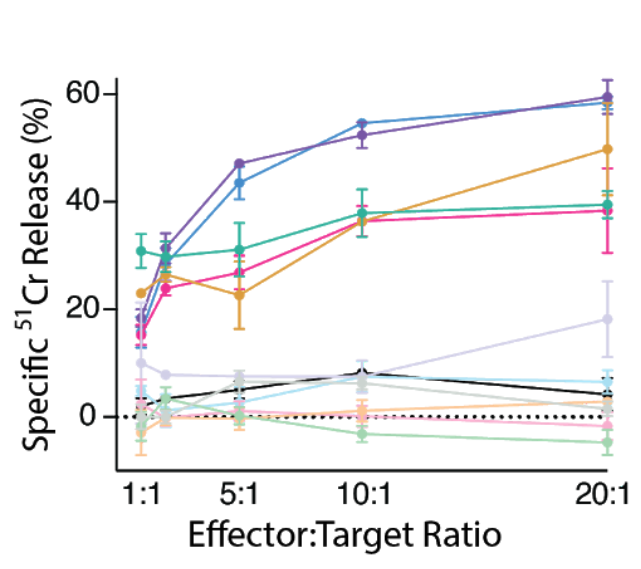

b Relative Cytotoxic Potency

MC57-HER2

Empty Vector

$\square$ Reference

$\square$ No-Cys

ProCAR-1

ProCAR-2

ProCAR-3

MC57-Parental

$\square$ Empty Vector

$\square$ Reference

$\square$ No-Cys

$\square$ ProCAR-1

ProCAR-2

ProCAR-3

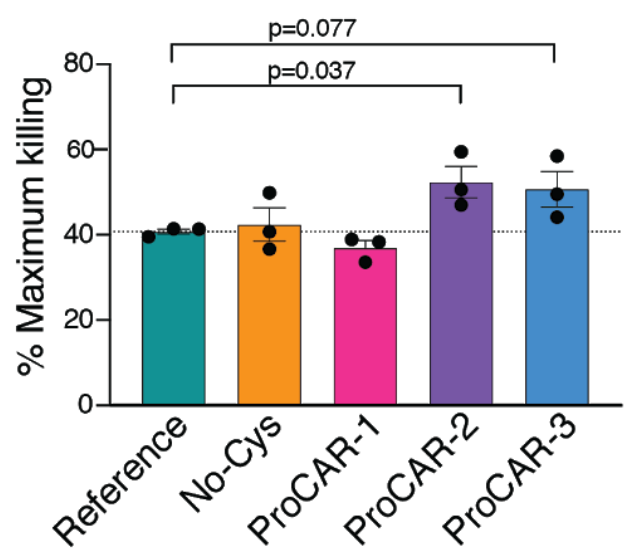

c MC57-HER2 co-culture
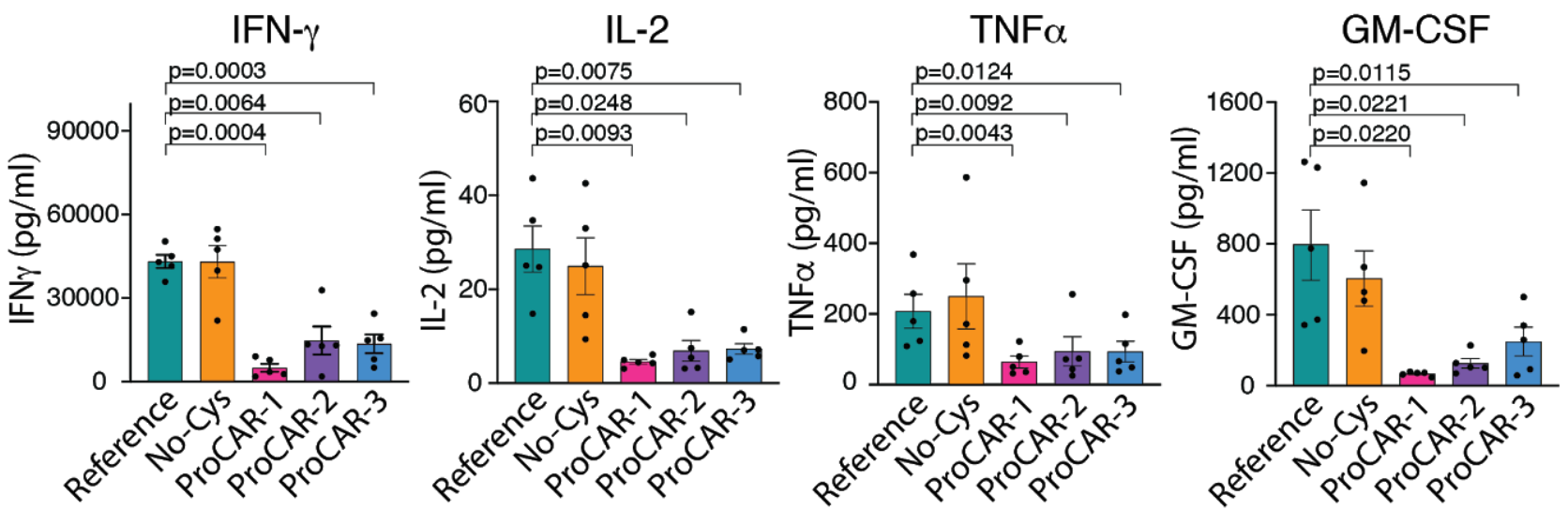

\section{d $\mathrm{CD} 3 / \mathrm{CD} 28$ bead co-culture}

IFN- $\gamma$

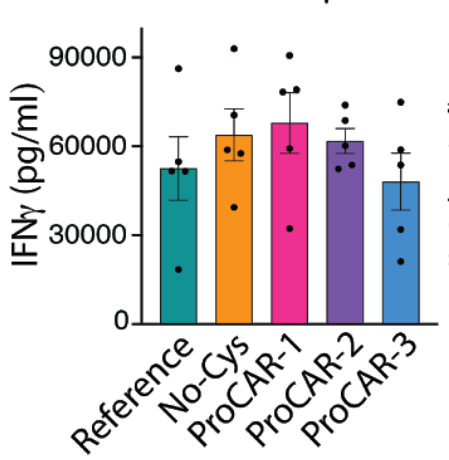

IL-2

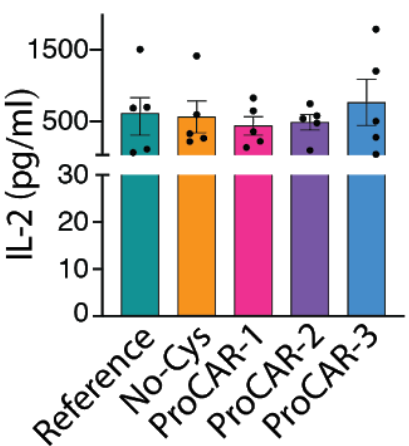

$\mathrm{TNF} \alpha$

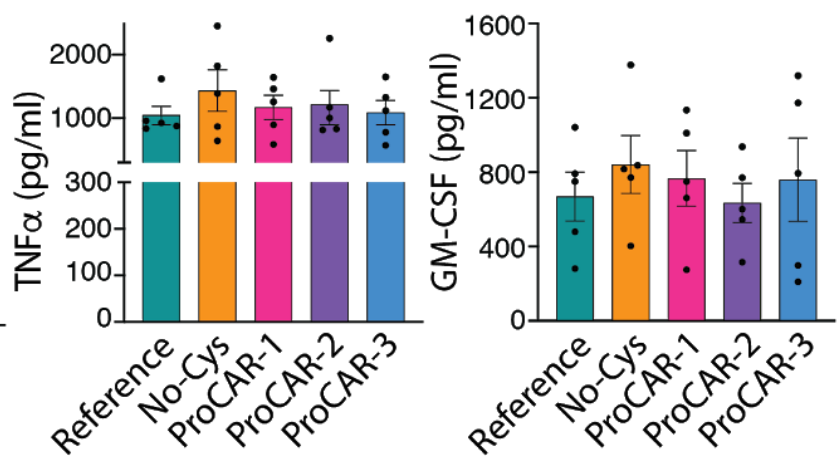

Figure 4: Tumour cell killing and cytokine production by HER2 proCAR-T cells. (a) A representative

four-hour ${ }^{51} \mathrm{Cr}$ release assay measuring cytotoxic potency of HER2-directed primary mouse proCAR-T cells against MC57-HER2 target tumour cells. Killing of antigen-negative MC57-Parental cells is shown in lighter colours. (b) Maximum target killing percentage at 20:1 effector to target ratio from all ${ }^{51} \mathrm{Cr}$ release assay experiments. Bars show mean \pm SEM with each data point representing an individual experiment $(n=3)$. P-values determined from paired $t$-tests. The dotted line marks mean maximum killing of the reference CAR construct for comparison. (c) Cytokine production by primary mouse HER2 proCAR-T cells co-cultured with 
MC57-HER2 target tumour cells or (d) control (antigen non-specific) CD3/CD28 Dynabeads ${ }^{\mathrm{TM}}$ for $24 \mathrm{hrs}^{.}$ Co-culture supernatants analysed using LEGENDplex T Helper Cytokine Panel Version 2 kit for IFN- $\gamma$, IL-2, TNF $\alpha$ and GM-CSF. Bars show mean concentration $(\mathrm{pg} / \mathrm{ml}) \pm$ SEM with each data point representing an individual experiment $(n=5)$. Significance was determined from paired $t$-tests. All data from individual experiments in this figure are shown separately in Figure S9 and S10.

Retroviral transduction of purified mouse primary $\mathrm{CD}^{+} \mathrm{T}$ cells yielded $41-70 \% \mathrm{CAR}^{+} \mathrm{T}$ cells and similar surface expression within each experiment for all proCARs (Supplemental Data Figure 8). In an in vitro cytotoxicity assay against human-HER2 ${ }^{+} \mathrm{MC57}$ mouse fibrosarcoma target cells (MC57-HER2), the reference CAR and monomeric HER2 proCAR-1 yielded similar potency, while proCAR-2 and proCAR-3 produced better killers despite their lack of stabilizing intermolecular disulphide bonds (Figure 4a). Combined data from three independent cytotoxicity experiments (all shown in Supplemental Data Figure 9) showed on average 25-30\% greater cytotoxic potency for the multimeric proCAR-2 and proCAR-3, while proCAR-1 was indistinguishable from the reference (Figure 4b). Additionally, all proCAR T cells exhibited strongly attenuated IFN $\gamma$, IL-2, TNF $\alpha$ and GM-CSF production when co-cultured with MC57-HER2 cells compared to the reference CAR (Figure 4c), with two- to ten-fold lower levels on average across five independent experiments (all cytokine measurements and controls shown in Supplemental Data Figure 10). This effect was specific to stimulation through the engineered receptors, since all CAR-T cells secreted similar high amounts of cytokines in response to control anti-CD3/anti-CD28 bead stimulation (Figure $\mathbf{4 d}$ and Supplemental Data Figure 10). This independent modulation of cytotoxicity and cytokine release is best illustrated by comparing the disulphide-linked dimeric reference CAR with the non-covalently associated proCAR-2 dimer: replacing the CD28 TM domain with the proMP C2.1 sequence simultaneously conferred $30 \%$ greater cytotoxicity (Figure $4 \mathbf{b}$ ), 4-fold lower IFN $\gamma$ and IL-2, 2.5-fold lower TNF $\alpha$ and 4.5-fold lower GM-CSF secretion (Figure 4c). CAR-T cell functions were antigen- and CAR-specific since T cells transduced with an empty vector showed low cytotoxic activity (Supplemental Data Figure 9) and responses to antigen-negative MC57 target cells were minimal for all CARs tested (Supplemental Data Figure 10). While there was some variability in proCAR surface expression across experiments (Supplemental Data Figure 8), these differences did not correlate with differences in cytotoxic potency or cytokine secretion.

Our results are consistent with a model in which the choice of CAR TMD can independently modulate antigen-specific cytotoxicity and cytokine release through distinct mechanisms. First, our observations that proCAR-2 and -3 , which are structurally very different, produce levels of 
killing that are similar to each other and higher than proCAR-1 suggest that TMD-driven oligomerization supports strong cytotoxic activity but the fine structural details may be less important. Second, the finding that all of the de novo designed TMDs, including the monomer, produced similar low levels of cytokine release indicates that the CD28 TMD sequence they replaced drives high cytokine release through features that are not necessarily related to the oligomeric state of the reference CAR and are absent in the proMPs. Thus, the designed proMP toolbox demonstrates that cytotoxicity and cytokine release are responsive to different properties of CAR TMDs and that significant control over CAR-T cell functions can be achieved without changing any extracellular or intracellular CAR sequences.

\section{Discussion}

This work establishes new de novo TMD design principles and illustrates their application to the rapidly developing field of engineered receptors, highlighting their usefulness in producing specific membrane-spanning self-assembling sequences of defined order. It demonstrates that TMD design, selection, structural validation and incorporation into synthetic receptors for therapeutic applications is feasible and can provide specific and highly desirable functional properties.

The ability to attenuate CAR-T cell cytokine release while enhancing cytotoxic potency has important implications for the safety and efficacy of cellular immunotherapies. Dangerously high levels of inflammatory cytokine production early after infusion cause the most commonly observed toxicity in CAR-T cell treatments, known as cytokine release syndrome (CRS), which is characterised by fever, hypotension, respiratory distress and multi-organ failure that can be fatal if not carefully managed (Gutierrez et al., 2018; Morgan et al., 2010). CRS is dose-limiting and often necessitates additional interventions, with the IL- 6 blocking antibody tocilizumab currently the front-line treatment (Maude et al., 2014). Pre-clinical studies have also shown that disarming GM-CSF alone using CRISPR inactivation in CAR-T cells or administering blocking antibodies significantly reduces CRS-like symptoms in vitro and in patient-derived xenograft models (Sachdeva et al., 2019; Sterner et al., 2019). Importantly, two recent phase-I clinical trials (Brudno et al., 2020; Ying et al., 2019) have shown that broadly attenuated CAR-T cell cytokine release can lead to reduced incidence of high-grade CRS and neurotoxicity without compromising the anti-tumour potency of CD19-directed CAR-T cell therapy in B-cell lymphoma patients. In one study (Brudno et al., 2020), reduced cytokine release was linked in part to replacing the CD28 hinge-TMD sequences with those from $\operatorname{CD} 8 \alpha$ in the CAR constructs. In another, small 
modifications at the edges of the $\operatorname{CD} 8 \alpha$ hinge-TMD sequence produced similar effects (Ying et al., 2019). While the mechanisms underlying the altered functional characteristics in these studies are unknown, they are consistent with a growing view that these domains can have a significant impact on CAR function. They also suggest that the in vitro functional profile of our proCAR-T cells, with enhanced tumor-cell killing and attenuated cytokine release, could provide substantial therapeutic benefit if supported by sufficient expansion and robust long-term proCAR-T cell survival in vivo. This will need to be tested in mouse models of human HER2 ${ }^{+}$cancers, and our proMP incorporation should be extended to other CAR-T cell specificities to assess the generality of these functional characteristics.

Mechanistically, our data show that the high cytokine secretion driven by the HER2-CD8-CD28- $\zeta$ CAR is directly linked to the 23-amino-acid CD28 TMD itself. This effect could be related to a highly conserved self-association motif recently identified in the CD28 TMD (Leddon et al., 2020) that is very similar to motifs that stabilize $\zeta \zeta$ TMD homodimers and the TCR $\alpha \beta$ TMD heterodimer (Call et al., 2006; Dong et al., 2019; Krshnan et al., 2016) and may therefore drive unintended interactions between CARs and endogenous CD28 to enhance cytokine production. The orthogonal nature of our de novo designs provides an elegant solution to this problem by insulating the proCAR from interactions driven by repurposed natural TMDs while also conferring an unprecedented degree of control over the formation of higher-order CAR structures, which provide enhanced cytotoxicity. While the trimer did not provide additional advantages over the dimer in this study, this may be due to saturated activation potential (James, 2018; Majzner et al., 2020) and the generality of this conclusion must be tested in comparisons among multiple designs of the same oligomeric order. Nonetheless, the ability to control receptor activity using modular TMDs may be particularly important for broadly expressed solid-tumour antigens such as HER2, where modulating receptor sensitivity through the selection of variable-affinity HER2-binding scFvs (Liu et al., 2015, 2017) facilitated the production of CAR-T cells that were responsive to HER2-high tumour cells but not to healthy tissues expressing lower levels of the antigen. Unlike the complex processes of mutating and selecting variable-affinity antigen-binding domains or empirically testing combinatorial multi-domain modifications in different CAR formats, the proCAR platform has the potential to be easily implemented on the background of any existing single-chain CAR designs and combined with other modifications to extracellular or intracellular sequences. We anticipate that the proMP design methods and sequences will find additional 
bioRxiv preprint doi: https://doi.org/10.1101/2020.07.26.221598; this version posted July 26,2020 . The copyright holder for this preprint (which was not certified by peer review) is the author/funder, who has granted bioRxiv a license to display the preprint in perpetuity. It is made available under aCC-BY-NC-ND 4.0 International license.

applications for controlling inter-molecular cell-surface protein interactions in a wide array of synthetic and biological systems.

\section{References}

Alabanza, L., Pegues, M., Geldres, C., Shi, V., Wiltzius, J.J.W., Sievers, S.A., Yang, S., and Kochenderfer, J.N. (2017). Function of Novel Anti-CD19 Chimeric Antigen Receptors with Human Variable Regions Is Affected by Hinge and Transmembrane Domains. Mol. Ther. 25, 2452-2465.

Arkhipov, A., Shan, Y., Das, R., Endres, N.F., Eastwood, M.P., Wemmer, D.E., Kuriyan, J., and Shaw, D.E. (2013). Architecture and membrane interactions of the EGF receptor. Cell 152, 557-569.

Balakrishnan, A., Rajan, A., Salter, A.I., Kosasih, P.L., Wu, Q., Voutsinas, J., Jensen, M.C., Plückthun, A., and Riddell, S.R. (2019). Multispecific Targeting with Synthetic Ankyrin Repeat Motif Chimeric Antigen Receptors. Clin. Cancer Res. 25, 7506-7516.

Barth, P., and Senes, A. (2016). Toward high-resolution computational design of the structure and function of helical membrane proteins. Nat. Struct. Mol. Biol. 23, 475-480.

Berry, R., and Call, M.E. (2017). Modular Activating Receptors in Innate and Adaptive Immunity. Biochemistry 56, 1383-1402.

Bowie, J.U. (1997). Helix packing in membrane proteins. J. Mol. Biol. 272, 780-789.

Bridgeman, J.S., Hawkins, R.E., Bagley, S., Blaylock, M., Holland, M., and Gilham, D.E. (2010). The optimal antigen response of chimeric antigen receptors harboring the CD3zeta transmembrane domain is dependent upon incorporation of the receptor into the endogenous TCR/CD3 complex. J. Immunol. 184, 6938-6949.

Bridgeman, J.S., Ladell, K., Sheard, V.E., Miners, K., Hawkins, R.E., Price, D.A., and Gilham, D.E. (2014). $\mathrm{CD} 3 \zeta$-based chimeric antigen receptors mediate $T$ cell activation via cis- and trans-signalling mechanisms: implications for optimization of receptor structure for adoptive cell therapy. Clin. Exp. Immunol. 175, 258-267.

Brudno, J.N., Lam, N., Vanasse, D., Shen, Y.-W., Rose, J.J., Rossi, J., Xue, A., Bot, A., Scholler, N., Mikkilineni, L., et al. (2020). Safety and feasibility of anti-CD19 CAR T cells with fully human binding domains in patients with B-cell lymphoma. Nat. Med. 26, 270-280.

Call, M.E., Pyrdol, J., Wiedmann, M., and Wucherpfennig, K.W. (2002). The organizing principle in the formation of the T cell receptor-CD3 complex. Cell 111, 967-979.

Call, M.E., Schnell, J.R., Xu, C., Lutz, R.A., Chou, J.J., and Wucherpfennig, K.W. (2006). The structure of the zetazeta transmembrane dimer reveals features essential for its assembly with the T cell receptor. Cell 127, 355-368.

Cosson, P., Lankford, S.P., Bonifacino, J.S., and Klausner, R.D. (1991). Membrane protein association by potential intrarnembrane charge pairs. Nature 351, 414-416.

Das, R., Andre, I., Shen, Y., Wu, Y., Lemak, A., Bansal, S., Arrowsmith, C.H., Szyperski, T., and Baker, D. (2009). Simultaneous prediction of protein folding and docking at high resolution. Proc. Natl. Acad. Sci. U. S. A. $106,18978-18983$.

Davenport, A.J., Jenkins, M.R., Cross, R.S., Yong, C.S., Prince, H.M., Ritchie, D.S., Trapani, J.A., Kershaw, M.H., Darcy, P.K., and Neeson, P.J. (2015). CAR-T Cells Inflict Sequential Killing of Multiple Tumor Target 
Cells. Cancer Immunol Res 3, 483-494.

Dong, D., Zheng, L., Lin, J., Zhang, B., Zhu, Y., Li, N., Xie, S., Wang, Y., Gao, N., and Huang, Z. (2019).

Structural basis of assembly of the human T cell receptor-CD3 complex. Nature 573, 546-552.

Elazar, A., Weinstein, J., Biran, I., Fridman, Y., Bibi, E., and Fleishman, S.J. (2016a). Mutational scanning reveals the determinants of protein insertion and association energetics in the plasma membrane. Elife 5 , 12125.

Elazar, A., Weinstein, J.J., Prilusky, J., and Fleishman, S.J. (2016b). Interplay between hydrophobicity and the positive-inside rule in determining membrane-protein topology. Proc. Natl. Acad. Sci. U. S. A. 113, 10340-10345.

Endres, N.F., Das, R., Smith, A.W., Arkhipov, A., Kovacs, E., Huang, Y., Pelton, J.G., Shan, Y., Shaw, D.E., Wemmer, D.E., et al. (2013). Conformational coupling across the plasma membrane in activation of the EGF receptor. Cell 152, 543-556.

Eshhar, Z., Waks, T., Gross, G., and Schindler, D.G. (1993). Specific activation and targeting of cytotoxic lymphocytes through chimeric single chains consisting of antibody-binding domains and the gamma or zeta subunits of the immunoglobulin and T-cell receptors. Proc. Natl. Acad. Sci. U. S. A. 90, 720-724.

Faham, S., Yang, D., Bare, E., Yohannan, S., Whitelegge, J.P., and Bowie, J.U. (2004). Side-chain Contributions to Membrane Protein Structure and Stability. J. Mol. Biol. 335, 297-305.

Fleishman, S.J., and Baker, D. (2012). Role of the biomolecular energy gap in protein design, structure, and evolution. Cell 149, 262-273.

Fleishman, S.J., Schlessinger, J., and Ben-Tal, N. (2002). A putative molecular-activation switch in the transmembrane domain of erbB2. Proc. Natl. Acad. Sci. U. S. A. 99, 15937-15940.

Fu, Q., Fu, T.-M., Cruz, A.C., Sengupta, P., Thomas, S.K., Wang, S., Siegel, R.M., Wu, H., and Chou, J.J. (2016). Structural Basis and Functional Role of Intramembrane Trimerization of the Fas/CD95 Death Receptor. Mol. Cell 61, 602-613.

Fujiwara, K., Tsunei, A., Kusabuka, H., Ogaki, E., Tachibana, M., and Okada, N. (2020). Hinge and Transmembrane Domains of Chimeric Antigen Receptor Regulate Receptor Expression and Signaling Threshold. Cells 9.

Gutierrez, C., McEvoy, C., Mead, E., Stephens, R.S., Munshi, L., Detsky, M.E., Pastores, S.M., and Nates, J.L. (2018). Management of the Critically III Adult Chimeric Antigen Receptor-T Cell Therapy Patient: A Critical Care Perspective. Crit. Care Med. 46, 1402-1410.

Haynes, N.M., Trapani, J.A., Teng, M.W.L., Jackson, J.T., Cerruti, L., Jane, S.M., Kershaw, M.H., Smyth, M.J., and Darcy, P.K. (2002). Single-chain antigen recognition receptors that costimulate potent rejection of established experimental tumors. Blood 100, 3155-3163.

Hennecke, S., and Cosson, P. (1993). Role of transmembrane domains in assembly and intracellular transport of the CD8 molecule. J. Biol. Chem. 268, 26607-26612.

James, J.R. (2018). Tuning ITAM multiplicity on T cell receptors can control potency and selectivity to ligand density. Science Signaling 11, eaan1088.

Joh, N.H., Wang, T., Bhate, M.P., Acharya, R., Wu, Y., Grabe, M., Hong, M., Grigoryan, G., and DeGrado, W.F. (2014). De novo design of a transmembrane Zn2+-transporting four-helix bundle. Science 346, 1520-1524.

June, C.H., O'Connor, R.S., Kawalekar, O.U., Ghassemi, S., and Milone, M.C. (2018). CAR T cell 
bioRxiv preprint doi: https://doi.org/10.1101/2020.07.26.221598; this version posted July 26,2020 . The copyright holder for this preprint (which was not certified by peer review) is the author/funder, who has granted bioRxiv a license to display the preprint in perpetuity. It is made available under aCC-BY-NC-ND 4.0 International license.

immunotherapy for human cancer. Science 359, 1361-1365.

Korendovych, I.V., and DeGrado, W.F. (2020). De novo protein design, a retrospective. Q. Rev. Biophys. 53, e3.

Krshnan, L., Park, S., Im, W., Call, M.J., and Call, M.E. (2016). A conserved $\alpha \beta$ transmembrane interface forms the core of a compact T-cell receptor-CD3 structure within the membrane. Proc. Natl. Acad. Sci. U. S. A. 113, E6649-E6658.

Langosch, D., Brosig, B., Kolmar, H., and Fritz, H.J. (1996). Dimerisation of the glycophorin A transmembrane segment in membranes probed with the ToxR transcription activator. J. Mol. Biol. 263, 525-530.

Leddon, S.A., Fettis, M.M., Abramo, K., Kelly, R., Oleksyn, D., and Miller, J. (2020). The CD28 Transmembrane Domain Contains an Essential Dimerization Motif.

Lemmon, M.A., Flanagan, J.M., Hunt, J.F., Adair, B.D., Bormann, B.J., Dempsey, C.E., and Engelman, D.M. (1992). Glycophorin A dimerization is driven by specific interactions between transmembrane alpha-helices. J. Biol. Chem. 267, 7683-7689.

Liu, X., Jiang, S., Fang, C., Yang, S., Olalere, D., Pequignot, E.C., Cogdill, A.P., Li, N., Ramones, M., Granda, B., et al. (2015). Affinity-Tuned ErbB2 or EGFR Chimeric Antigen Receptor T Cells Exhibit an Increased Therapeutic Index against Tumors in Mice. Cancer Res. 75, 3596-3607.

Liu, X., Zhang, N., and Shi, H. (2017). Driving better and safer HER2-specific CARs for cancer therapy. Oncotarget 8, 62730-62741.

Lu, P., Min, D., DiMaio, F., Wei, K.Y., Vahey, M.D., Boyken, S.E., Chen, Z., Fallas, J.A., Ueda, G., Sheffler, W., et al. (2018). Accurate computational design of multipass transmembrane proteins. Science 359, 1042-1046.

Majzner, R.G., and Mackall, C.L. (2019). Clinical lessons learned from the first leg of the CAR T cell journey. Nat. Med. 25, 1341-1355.

Majzner, R.G., Rietberg, S.P., Sotillo, E., Dong, R., Vachharajani, V.T., Labanieh, L., Myklebust, J.H., Kadapakkam, M., Weber, E.W., Tousley, A.M., et al. (2020). Tuning the Antigen Density Requirement for CAR T Cell Activity. Cancer Discov.

Mata, M., and Gottschalk, S. (2019). Engineering for Success: Approaches to Improve Chimeric Antigen Receptor T Cell Therapy for Solid Tumors. Drugs 79, 401-415.

Matthews, E.E., Zoonens, M., and Engelman, D.M. (2006). Dynamic helix interactions in transmembrane signaling. Cell 127, 447-450.

Maude, S.L., Barrett, D., Teachey, D.T., and Grupp, S.A. (2014). Managing cytokine release syndrome associated with novel T cell-engaging therapies. Cancer J. 20, 119-122.

Morgan, R.A., Yang, J.C., Kitano, M., Dudley, M.E., Laurencot, C.M., and Rosenberg, S.A. (2010). Case report of a serious adverse event following the administration of $T$ cells transduced with a chimeric antigen receptor recognizing ERBB2. Mol. Ther. 18, 843-851.

Pan, L., Fu, T.-M., Zhao, W., Zhao, L., Chen, W., Qiu, C., Liu, W., Liu, Z., Piai, A., Fu, Q., et al. (2019). Higher-Order Clustering of the Transmembrane Anchor of DR5 Drives Signaling. Cell 176, 1477-1489.e14.

Rafiq, S., Hackett, C.S., and Brentjens, R.J. (2020). Engineering strategies to overcome the current roadblocks in CAR T cell therapy. Nature Reviews Clinical Oncology 17, 147-167.

Rutledge, T., Cosson, P., Manolios, N., Bonifacino, J.S., and Klausner, R.D. (1992). Transmembrane helical 
interactions: zeta chain dimerization and functional association with the T cell antigen receptor. EMBO J. $11,3245-3254$.

Sachdeva, M., Duchateau, P., Depil, S., Poirot, L., and Valton, J. (2019). Granulocyte-macrophage colony-stimulating factor inactivation in CAR T-cells prevents monocyte-dependent release of key cytokine release syndrome mediators. J. Biol. Chem. 294, 5430-5437.

Salter, A.I., Pont, M.J., and Riddell, S.R. (2018). Chimeric antigen receptor-modified T cells: CD19 and the road beyond. Blood 131, 2621-2629.

Sterner, R.M., Sakemura, R., Cox, M.J., Yang, N., Khadka, R.H., Forsman, C.L., Hansen, M.J., Jin, F., Ayasoufi, K., Hefazi, M., et al. (2019). GM-CSF inhibition reduces cytokine release syndrome and neuroinflammation but enhances CAR-T cell function in xenografts. Blood 133, 697-709.

Weinstein, J.Y., Elazar, A., and Fleishman, S.J. (2019). A lipophilicity-based energy function for membrane-protein modelling and design. PLoS Comput. Biol. 15, e1007318.

Wels, W., Harwerth, I.M., Zwickl, M., Hardman, N., Groner, B., and Hynes, N.E. (1992). Construction, bacterial expression and characterization of a bifunctional single-chain antibody-phosphatase fusion protein targeted to the human erbB-2 receptor. Biotechnology 10, 1128-1132.

Woodall, N.B., Yin, Y., and Bowie, J.U. (2015). Dual-topology insertion of a dual-topology membrane protein. Nat. Commun. 6, 8099.

Ying, Z., Huang, X.F., Xiang, X., Liu, Y., Kang, X., Song, Y., Guo, X., Liu, H., Ding, N., Zhang, T., et al. (2019). A safe and potent anti-CD19 CAR T cell therapy. Nat. Med. 25, 947-953.

\section{Acknowledgements}

We acknowledge the use of the CSIRO Collaborative Crystallisation Centre (C3) for crystallisation screening. X-ray diffraction data were collected at the MX2 beamline of the Australian Synchrotron and we thank the beamline scientists for their technical support. Research supported by a Consolidator's Grant from the European Research Council (815379) and a charitable donation from Sam Switzer and family (to S.J.F.), Australian National Health and Medical Research Council (NHMRC) Project Grant 1158249 (to M.E.C., M.J.C., S.J.F. and M.R.J.) and IRIISS Infrastructure Support (to WEHI), Victorian State Government Operational Infrastructure Support (to WEHI), research grants from the Harry Secomb Foundation and the Percy Baxter Charitable Trust (to M.E.C.) and an equipment grant from the Harold and Cora Brennen Benevolent Trust (to M.E.C.).

\section{Author Contributions}

A.E., J.W., and S.J.F conceived and developed the proMP modelling and design methods and A.E. and J.W. computed the designs. A.E. experimentally tested the designs' bacterial expression and self-association profiles. N.J.C., J.V.N., R.T. and M.E.C. produced and purified proMP peptides and performed crystallisation screening. N.J.C., J.V.N., R.T. and M.J.C. determined crystal structures. N.J.C. designed and constructed proCARs and performed and analysed all experiments in cell lines. A.S.D., N.J.C., M.R.J., M.E.C. and M.J.C designed primary T cell experiments and A.S.D. performed and analysed all experiments in primary T cells. M.E.C. and M.J.C. conceived and supervised proMP peptide production and structure determination strategies and proCAR-T cell design and testing strategies. S.J.F. supervised the design process and bacterial expression and self-association experiments. M.E.C. and S.J.F. wrote the manuscript with input from A.E. and M.J.C.. All authors reviewed and edited drafts of the manuscript.

\section{Competing Interests}

A.E., N.J.C., J.W., M.J.C., M.E.C. and S.J.F. are listed as inventors on a patent application covering 
bioRxiv preprint doi: https://doi.org/10.1101/2020.07.26.221598; this version posted Julv 26, 2020. The copvright holder for this preprint (which was not certified by peer review) is the author/funder, who has granted bioRxiv a license to display the preprint in perpetuity. It is made available under aCC-BY-NC-ND 4.0 International license.

the proMP sequences and proCARs described herein.

\section{Materials and Correspondence}

Correspondence and requests for materials related to proMP design methods should be directed to S.J.F. sarel@weizmann.ac.il. Correspondence and requests for materials related to proMP structural analysis should be directed to M.J.C. micall@wehi.edu.au. Correspondence and requests for materials related to proCAR applications should be directed to M.E.C. mecall@wehi.edu.au. 


\section{Supplemental Data}

a Before Sequence Diversification PRRRLLLALLAAILAFLLGLLLAL

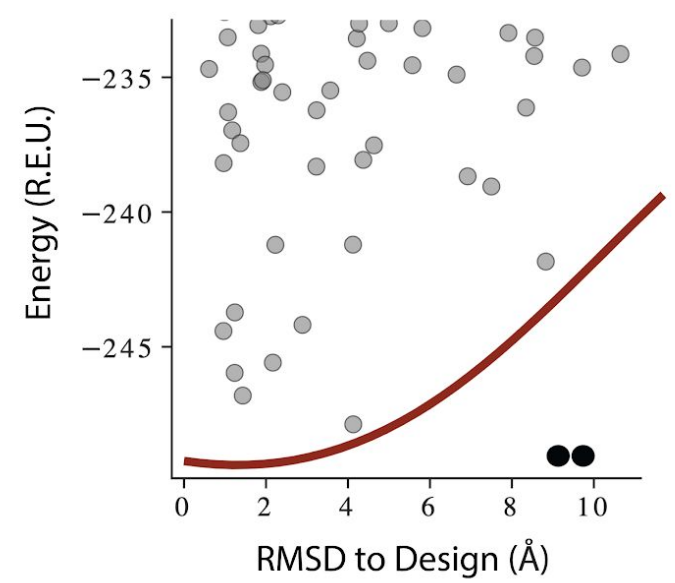

b After Sequence Diversification

PAFYIILAILTSFIAYLVGLLVSF

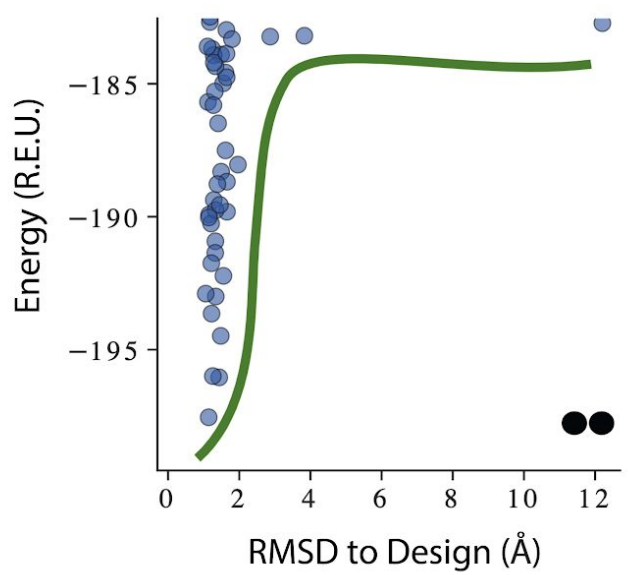

Supplemental Data Figure 1: A representative example of proMP sequence diversification resulting in the sequence for proMP 1.8. (a) de novo designed proMPs exhibited a high proportion of the large, flexible and hydrophobic amino acid Leu (boldface), in accordance with the high lipophilicity of this amino acid according to the $\mathrm{dsT} \beta \mathrm{L}$ lipophilicity scale. Forward folding $a b$ initio calculations in C2 symmetry, however, exhibited a flat energy landscape with multiple low-energy structures that diverged from the design. (b) Simulated annealing Monte Carlo simulations starting from the sequence in (a) augmented with a potential that biased sequence choices to the propensities observed in natural TMDs resulted in sequences with fewer Leu amino acids. Although the Rosetta energies of the designs prior to sequence diversification were more favourable than after (compare the $y$-axes of the two plots), the sequence-diversified sequences clearly converged to the designed structure. These results suggest that the sequence composition of natural TMDs encodes negative-design principles that ensure folding to a unique conformation. Red one-letter codes indicate positions at the homodimer interface; smooth red and green lines are visual aids. 

made available under aCC-BY-NC-ND 4.0 International license.

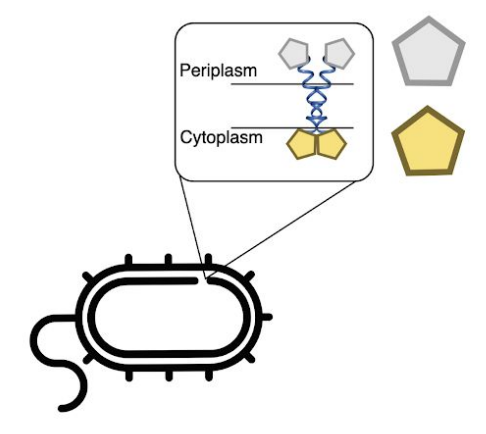

$\beta$-Lactamase (Ampicillin resistance): Membrane insertion

ToxR (Chloramphenicol resistance): Self-association

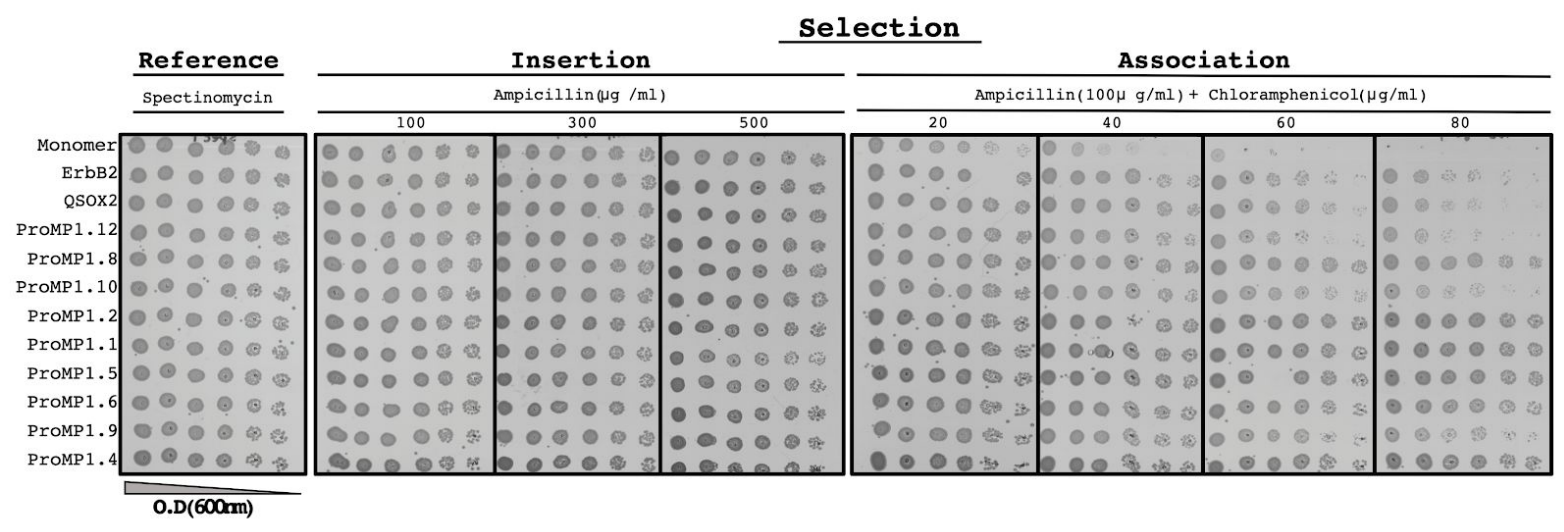

Supplemental Data Figure 2: The E. coli TOXCAT- $\beta$-lactamase (T $\beta$ L) selection system. (top) The construct comprises two selection domains, $\beta$ lactamase and the transcriptional activator ToxR of the chloramphenicol acetyltransferase. The former is only active in the periplasmic space; the latter depends on dimerisation and is only active in the cytoplasm. Therefore, this system selects bacteria that express a self-associating domain in the inner membrane. (bottom) Spectinomycin selects for transformed bacteria; ampicillin selects for membrane insertion; and ampicillin + chloramphenicol select for membrane insertion and self-association. All the constructs we tested are expressed in the inner membrane, as evidenced by the uniform resistance to ampicillin. The monomeric construct (the C-terminal portion of human L-selectin, CLS) serves as a negative control for self-association and ErbB2 and QSOX2 serve as positive controls based on the TMDs of the respective proteins. Many of the proMPs display a higher level of survival than the positive controls (e.g., 1.1, 1.2, 1.4, 1.5, 1.6, and 1.8). 

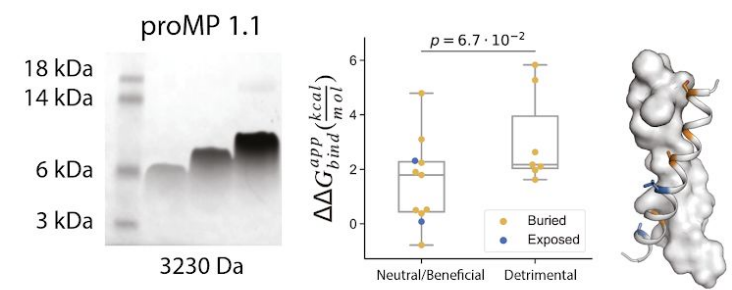

EPELSFLLGILAALVGFIIGFLAALIRRLC
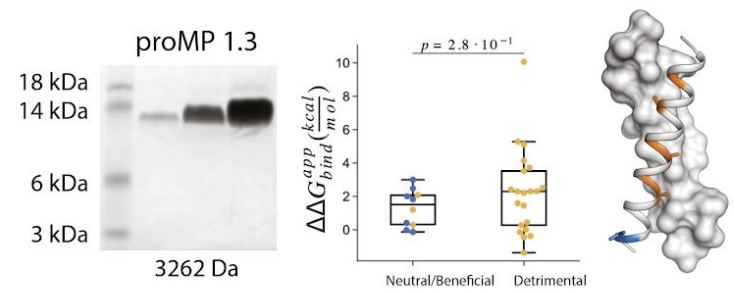

EPEILFAILAAFIGAFIAALFVLVLARRLC
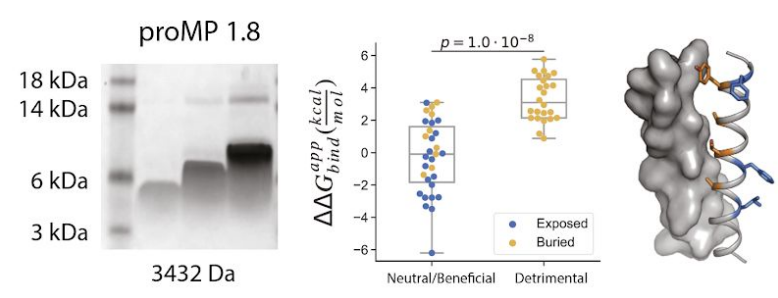

EPEAFYIILAILTSFIAYLVGLLVSFRRLC

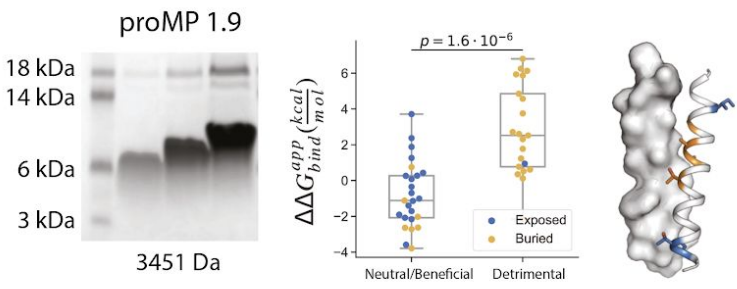

EPEIYVILAILAAVFTWFIVLITSLSRRLC

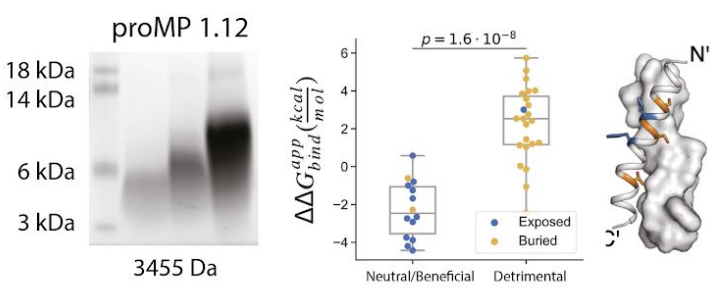

EPEIVLLLSLLASVFGAFITFIWAYLRRLC

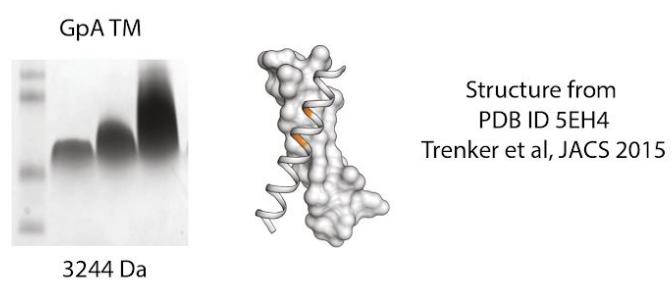

EPEITLIIFGVIAGVIGTILLISYGIRRLC

\section{Supplemental Data Figure 3: Additional design round 1 sequences, model structures, gel-shift} and deep mutational scanning analysis. Each design and a set of single-point mutants were introduced in selected positions (boldface) and assayed using the $\mathrm{T} \beta \mathrm{L}$ selection scheme. Amino acids that are positioned at the interface are in orange and those that are lipid-facing are in blue. The mutations were generated using DNA oligos with the degenerate codon NYS, encoding the amino acid identities: Ala, Val, Ile, Leu, Phe, Met, Ser, Thr and Pro (mutations to Pro were excluded from the analysis). We note that proMP 1.3, whose migration on SDS-PAGE indicates an oligomer larger than a dimer, also shows poor segregation of mutations at predicted interface versus lipid-exposed positions in $\mathrm{T} \beta \mathrm{L}$ selection, consistent with the formation of a structure that is different from the design model in this case. 


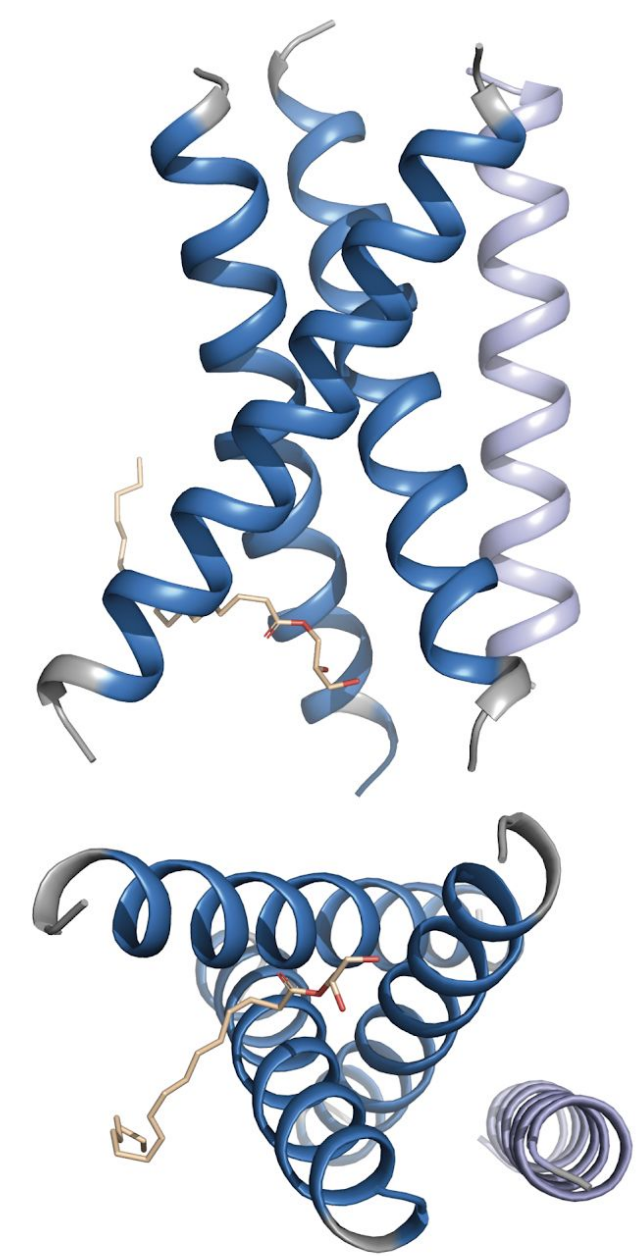

EPELLFILVAILGGLFGAIVAFLLALRRLC

\begin{tabular}{|c|c|}
\hline proMP 1.2 & PDB ID 6W9Y \\
\hline Wavelength & $0.953737 \AA$ \\
\hline Resolution range & $32.35-2.55(2.641-2.55)$ \\
\hline Space group & C 2221 \\
\hline Unit cell & 41.48964 .97585 .16909090 \\
\hline Total reflections & $19528(1899)$ \\
\hline Unique reflections & $3956(381)$ \\
\hline Multiplicity & $4.9(5.0)$ \\
\hline Completeness (\%) & $98.94(97.14)$ \\
\hline Mean I/sigma(I) & $12.72(2.41)$ \\
\hline Wilson B-factor & 60.27 \\
\hline R-merge & $0.06635(0.5728)$ \\
\hline$R$-meas & $0.07495(0.6397)$ \\
\hline R-pim & $0.0338(0.2793)$ \\
\hline $\mathrm{CCl} 1 / 2$ & $0.995(0.936)$ \\
\hline $\mathrm{CC}^{*}$ & $0.999(0.983)$ \\
\hline Reflections used in & $3935(374)$ \\
\hline Reflections used for R-free & $395(37)$ \\
\hline R-work & $0.2773(0.3131)$ \\
\hline R-free & $0.3259(0.2852)$ \\
\hline $\mathrm{CC}$ (work) & $0.942(0.867)$ \\
\hline $\mathrm{CC}$ (free) & $0.881(0.822)$ \\
\hline Number of non-hydrogen & 840 \\
\hline macromolecules & 815 \\
\hline ligands & 25 \\
\hline Protein residues & 108 \\
\hline RMS(bonds) & 0.001 \\
\hline RMS(angles) & 0.34 \\
\hline Ramachandran favored (\%) & 100.00 \\
\hline Ramachandran allowed (\%) & 0.00 \\
\hline Ramachandran outliers (\%) & 0.00 \\
\hline Rotamer outliers (\%) & 1.25 \\
\hline Clashscore & 3.86 \\
\hline Average B-factor & 86.13 \\
\hline macromolecules & 86.06 \\
\hline ligands & 88.42 \\
\hline Number of TLS groups & 4 \\
\hline
\end{tabular}

Values in parentheses are for highest resolution shell.

Supplemental Data Figure 4: ProMP 1.2 asymmetric unit and structure statistics. Crystals of proMP 1.2 were obtained via LCP crystallisation at $35 \mathrm{mg} / \mathrm{ml}$ peptide concentration as described in experimental methods. Screening was performed by the CSIRO Collaborative Crystallisation Centre (C3). Oblong hexagonal discs grown in $25 \% \mathrm{w} / \mathrm{v}$ polyethylene glycol $1500,10 \% \mathrm{v} / \mathrm{v}$ succinate-phosphate-glycine ( $\mathrm{pH}$ 6.0) were harvested and frozen in liquid nitrogen using $30 \%$ glycerol in precipitant solution as cryo-protectant. ProMP 1.2 packs in the crystal as a trimer (blue) with one monoolein molecule (wheat stick representation) and a less well-ordered helix that is antiparallel in orientation with respect to the trimer (light blue) in the asymmetric unit. Blue ribbons and text represent the designed sequence; gray ribbons and text represent the appended $\mathrm{N}$ - and C-terminal sequences included to aid production and crystallisation. 

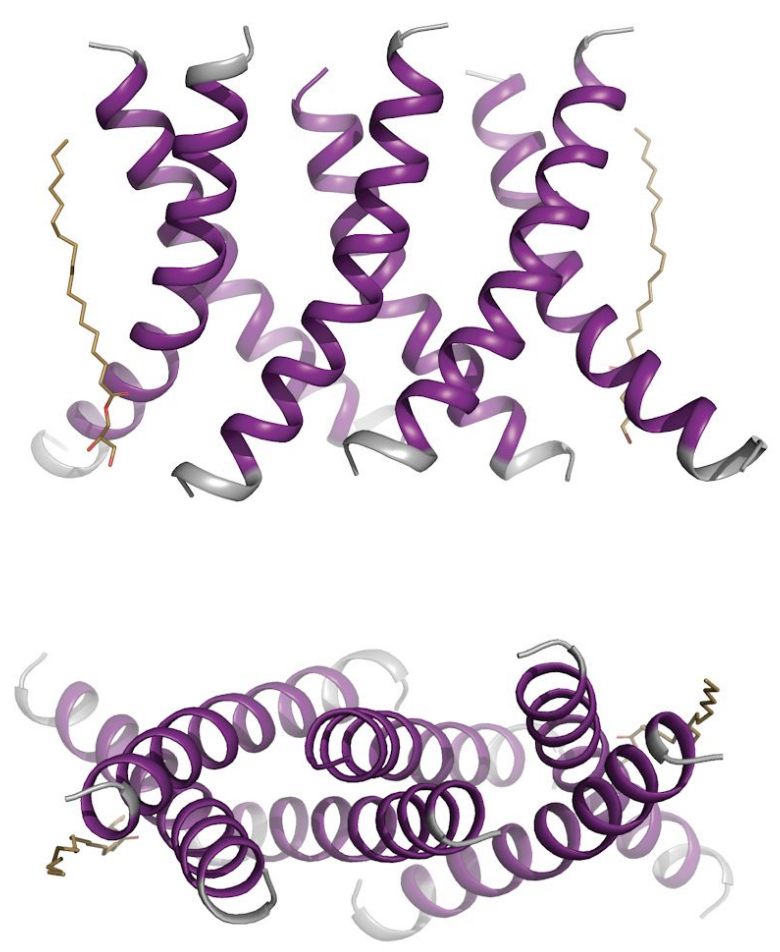

EPELTVALILGIFLGTF IAFWVVYLLRRLC

\begin{tabular}{ll} 
& \\
\hline proMP C2.1 & PDB ID 6W9Z \\
\hline Wavelength & $0.953737 \AA$ \\
Resolution range & $39.74-2.7(2.796-2.7)$ \\
Space group & P 2 21 21 1 \\
Unit cell & 44.156 .20591 .6379090 \\
Total reflections & $28994(2828)$ \\
Unique reflections & $6647(444)$ \\
Multiplicity & $4.4(4.4)$ \\
Completeness (\%) & $96.14(68.62)$ \\
Mean I/sigma(I) & $13.15(1.84)$ \\
Wilson B-factor & 34.89 \\
R-merge & $0.06678(0.8244)$ \\
R-meas & $0.07598(0.937)$ \\
R-pim & $0.0355(0.4376)$ \\
CC1/2 & $0.999(0.634)$ \\
CC* & $1(0.881)$ \\
Reflections used in refinement & $6409(444)$ \\
Reflections used for R-free & $642(45)$ \\
R-work & $0.2165(0.2248)$ \\
R-free & $0.2839(0.2451)$ \\
CC(work) & $0.917(0.865)$ \\
CC(free) & $0.918(0.721)$ \\
Number of non-hydrogen atoms & 1479 \\
macromolecules & 1427 \\
ligands & 50 \\
solvent & 2 \\
Protein residues & 173 \\
RMS(bonds) & 0.007 \\
RMS(angles) & 0.97 \\
Ramachandran favored (\%) & 99.35 \\
Ramachandran allowed (\%) & 0.65 \\
Ramachandran outliers (\%) & 0.00 \\
Rotamer outliers (\%) & 0.00 \\
Clashscore & 5.16 \\
Average B-factor & 35.54 \\
macromolecules & 35.40 \\
ligands & 39.64 \\
solvent & 35.23 \\
& \\
&
\end{tabular}

Values in parentheses are for highest resolution shell.

Supplemental Data Figure 5: ProMP C2.1 asymmetric unit and structure statistics. Crystals of proMP C2.1 were obtained via LCP crystallisation at $40 \mathrm{mg} / \mathrm{ml}$ peptide concentration as described in experimental methods. Screening was performed by the CSIRO Collaborative Crystallisation Centre (C3). Large rhomboid plates grown in 8\% v/v 2-methyl-2,4-pentanediol, $0.1 \mathrm{M}$ ADA (pH 6.7), $0.4 \mathrm{M}$ potassium nitrate, $0.1 \mathrm{M}$ tripotassium citrate were harvested and frozen in liquid nitrogen using 30\% glycerol in precipitant solution as cryo-protectant. ProMP C2.1 packs in the crystal as a trimer of dimers with two monoolein molecules (wheat stick representation) in the asymmetric unit. Purple ribbons and text represent the designed sequence; grey ribbons and text represent the appended $\mathrm{N}$ - and $\mathrm{C}$-terminal sequences included to aid production and crystallisation. 

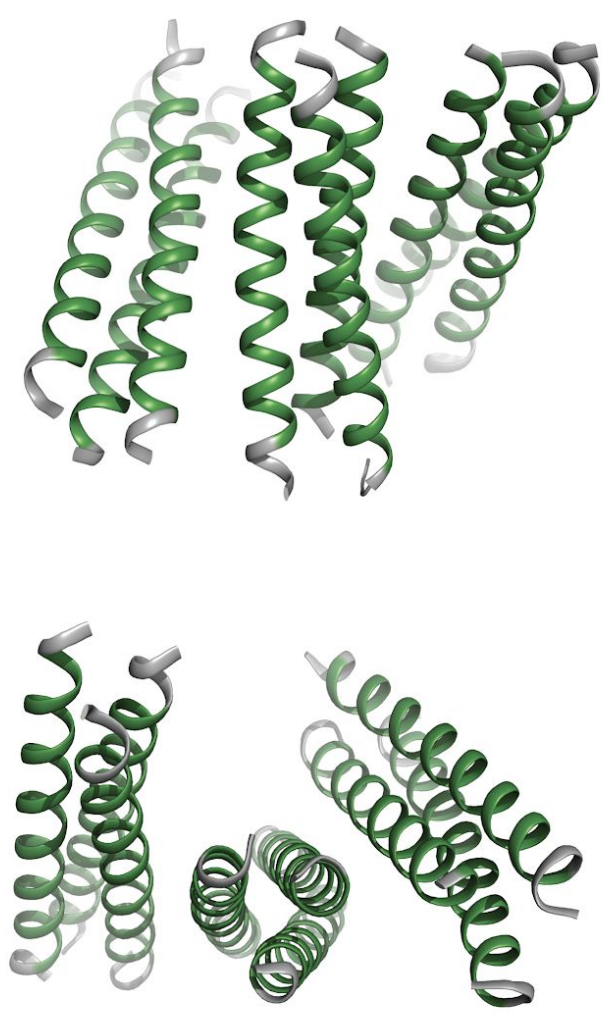

EPETALLVAFVAYYTALIALIFAILATRRLC

\begin{tabular}{ll}
\hline proMP C3.1 & PDB ID 6WA0 \\
\hline Wavelength & $0.953737 \AA$ \\
Resolution range & $36.87-3.484(3.608-3.484)$ \\
Space group & P 3221 \\
Unit cell & 96.15996 .15979 .2999090120 \\
Total reflections & $56923(5833)$ \\
Unique reflections & $5664(552)$ \\
Multiplicity & $10.0(10.5)$ \\
Completeness (\%) & $99.79(99.82)$ \\
Mean I/sigma(I) & $13.15(1.82)$ \\
Wilson B-factor & 118.94 \\
R-merge & $0.1423(1.341)$ \\
R-meas & $0.15(1.408)$ \\
R-pim & $0.047(0.4279)$ \\
CC1/2 & $0.999(0.728)$ \\
CC* & $1(0.918)$ \\
Reflections used in & $5658(552)$ \\
Reflections used for R-free & $565(58)$ \\
R-work & $0.2220(0.3140)$ \\
R-free & $0.2702(0.3447)$ \\
CC(work) & $0.953(0.789)$ \\
CC(free) & $0.933(0.574)$ \\
Number of non-hydrogen & 2106 \\
macromolecules & 2106 \\
Protein residues & 269 \\
RMS(bonds) & 0.002 \\
RMS(angles) & 0.44 \\
Ramachandran favored (\%) & 98.37 \\
Ramachandran allowed (\%) & 0.00 \\
Ramachandran outliers (\%) & 1.63 \\
Rotamer outliers (\%) & 0.50 \\
Clashscore & 2.28 \\
Average B-factor & 105.57 \\
macromolecules & 105.57 \\
&
\end{tabular}

Values in parentheses are for highest resolution shell.

Supplemental Data Figure 6: ProMP C3.1 asymmetric unit and structure statistics. Crystals of proMP C3.1 were obtained via sitting-drop vapour diffusion crystallisation at $10 \mathrm{mg} / \mathrm{ml}$ peptide in $30 \mathrm{mM} \mathrm{C}_{8} \mathrm{E}_{4}$ as described in experimental methods. Screening was performed by the CSIRO Collaborative Crystallisation Centre (C3). Small ellipsoid crystals grown in 65\% v/v 2-methyl-2,4-pentanediol, 0.1 M tris chloride $\mathrm{pH} 8.0$ were harvested and frozen in liquid nitrogen with no additional cryo-protectant. ProMP C3.1 packs in the crystal with a trimer of trimers in the asymmetric unit. Green ribbons and text represent the designed sequence; gray ribbons and text represent the appended $\mathrm{N}$ - and $\mathrm{C}$-terminal sequences included to aid production and crystallisation. 


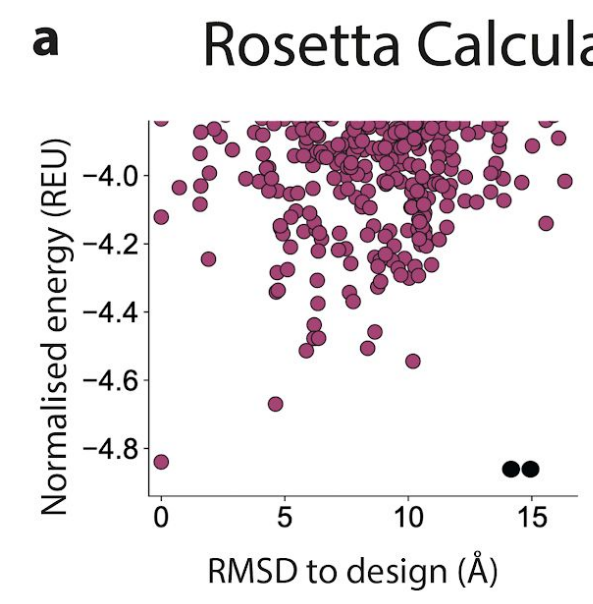

b
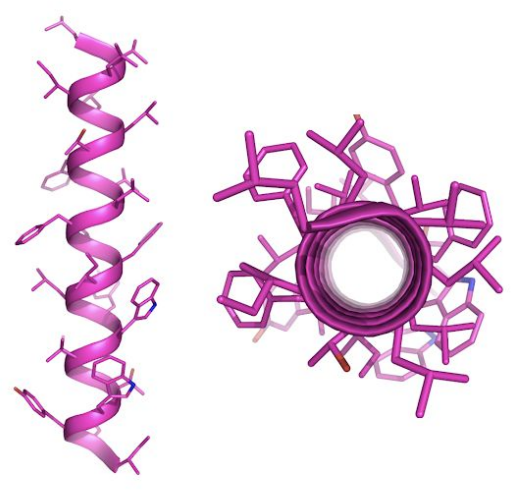

LVLILLTFVLFVFILYWVITWYLI

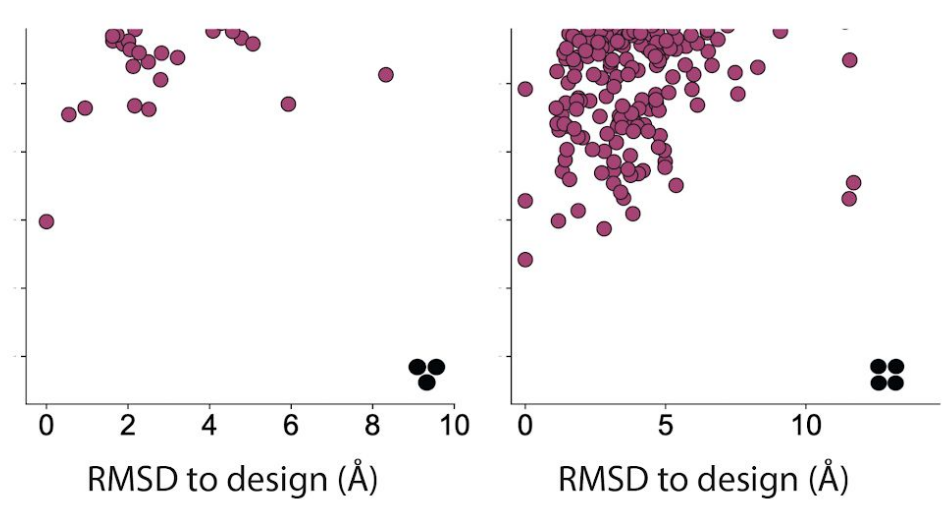

C

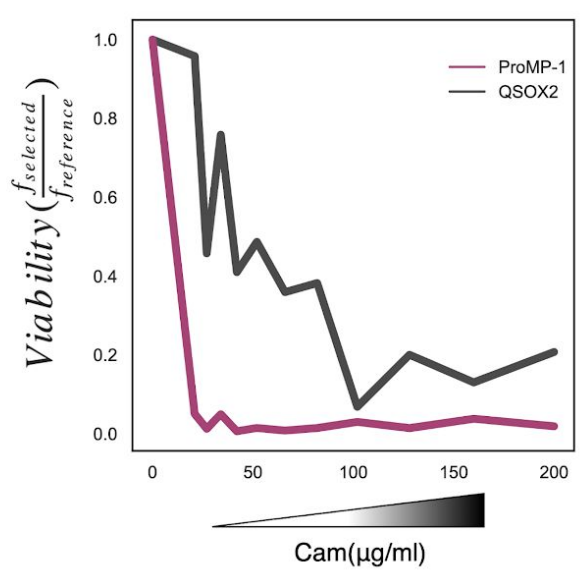

Supplemental Data Figure 7: Design of a highly expressed monomeric proMP (a) $A b$ initio structure predictions for proMP-1 in C2, C3 and C4 symmetries exhibit flat energy landscapes suggesting that the design would not form homo-oligomers. (b) The design model of proMP-1 shows no flat surfaces that are prone to self-association; yet, the sequence is highly hydrophobic with apparent insertion energy computed using the dsT $\beta \mathrm{L}$ scale of $-18.7 \mathrm{kcal} / \mathrm{mol}$ (compared to $-5.9 \mathrm{kcal} / \mathrm{mol}$ for a reference monomer [the human CLS sequence]). (c) the design is extremely sensitive to chloramphenicol in the dsT $\beta \mathrm{L}$ assay (compared to the weak natural homodimer QSOX2 which served as a reference), verifying that it does not form homo-oligomers. 
a Transduction Efficiency Gating Strategy
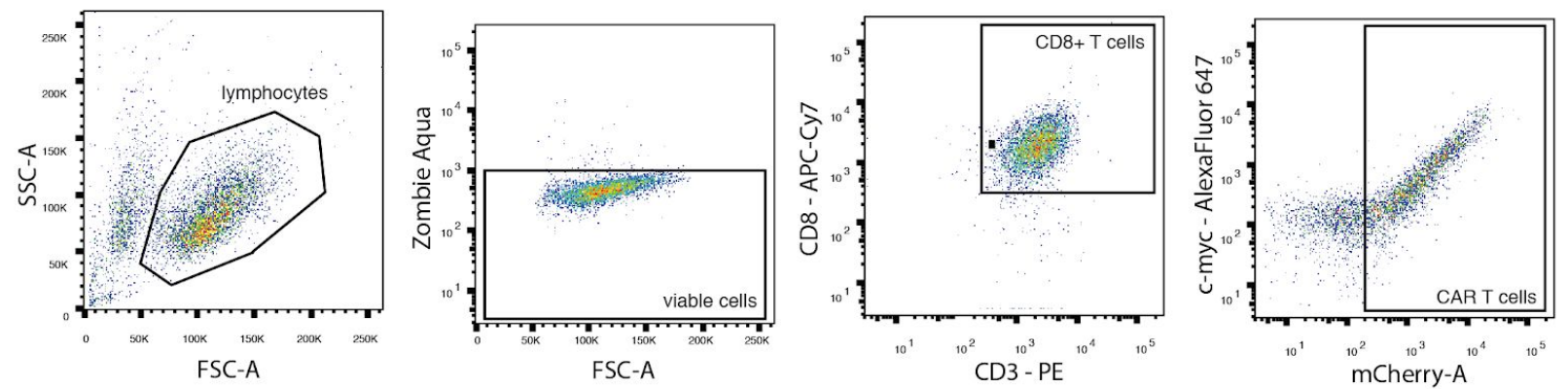

b Transduction Efficiency of murine CAR constructs
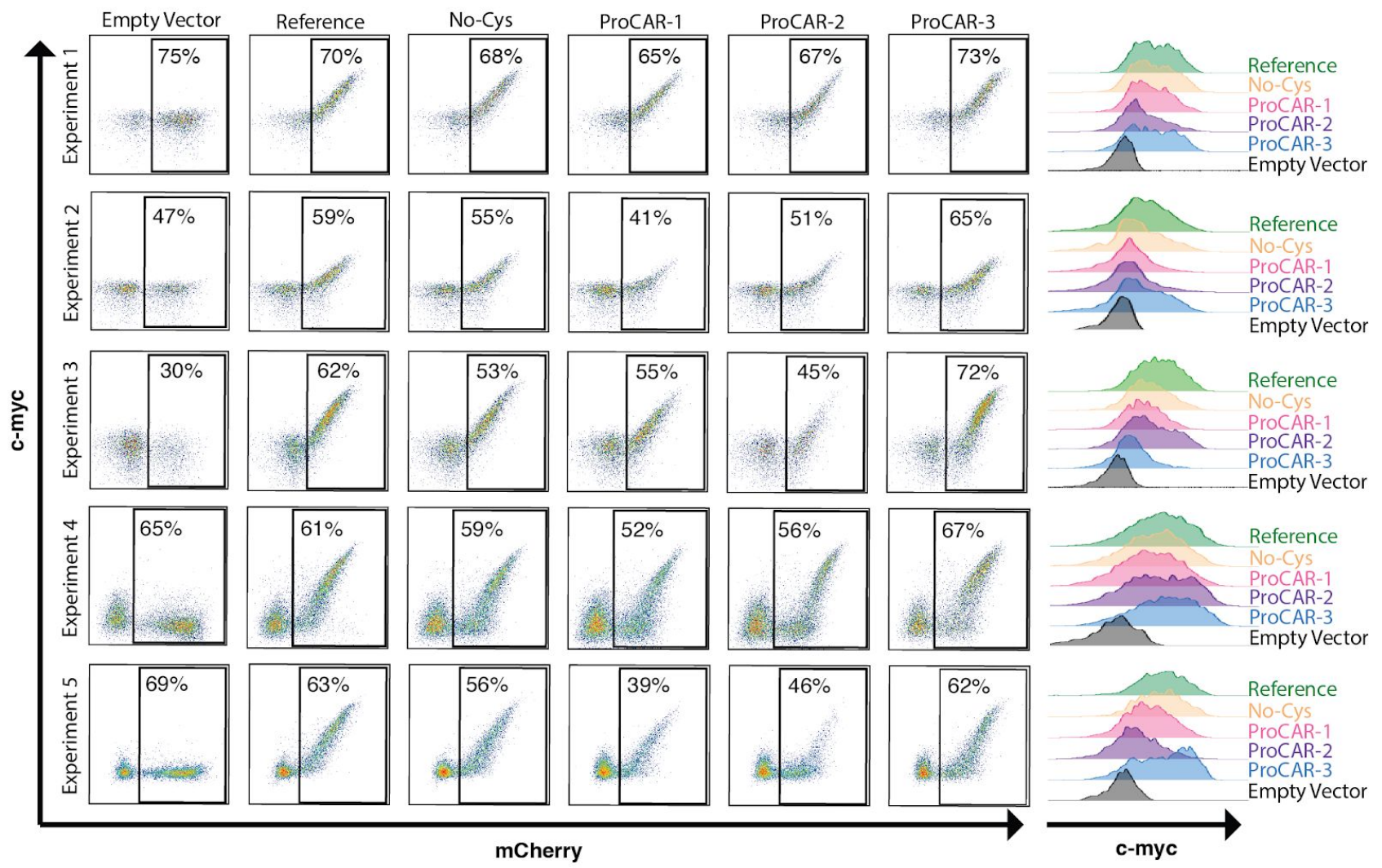

Supplemental Data Figure 8: Mouse CAR T cell gating strategy and transduction efficiency. (a)

Flow cytometry gating strategy to determine the transduction efficiency of primary murine CAR-T cells. Lymphocytes selected via morphology, live cells selected as zombie aqua negative, T cells selected as CD3+CD8+ and mCherry+ cells defined as CAR-T cells. C-myc co-expression with mCherry indicates surface CAR expression. (b) Flow cytometry of CD3+CD8+ T cells on day 5 post-transduction demonstrating the percentage of cells expressing CAR for 5 primary mouse CAR-T cell experiments. 2D Plots show extracellular c-myc labelling ( $y$-axis) vs. intracellular mCherry (x-axis). Histograms show extracellular c-myc labelling ( $x$-axis) on mCherry ${ }^{+}$gated CAR-T cells. Empty mCherry vector included as c-myc negative control. 


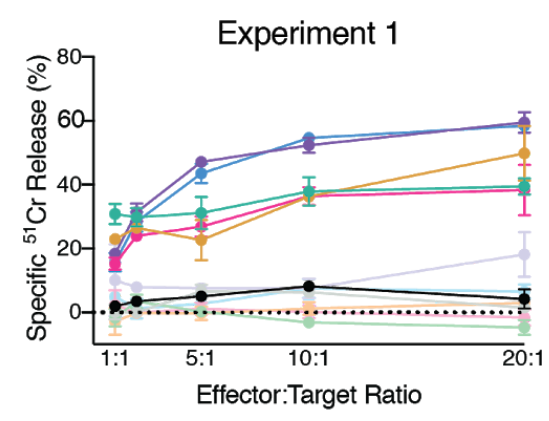

MC57 - HER2:

MC57 - Parental: $\square$ Empty Vector

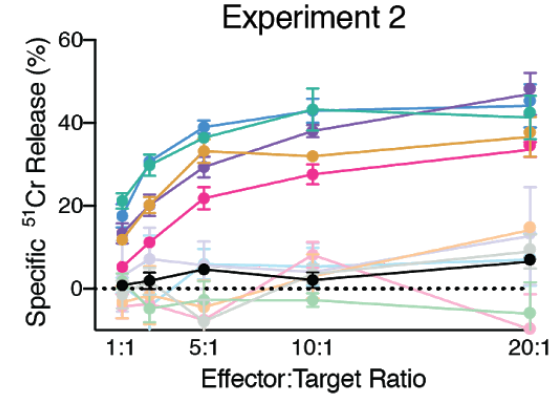

$\square$ Reference $\square$ No-Cys $\square$ ProCAR-1

$\square$ Reference $\square$ No-Cys $\square$ ProCAR-1

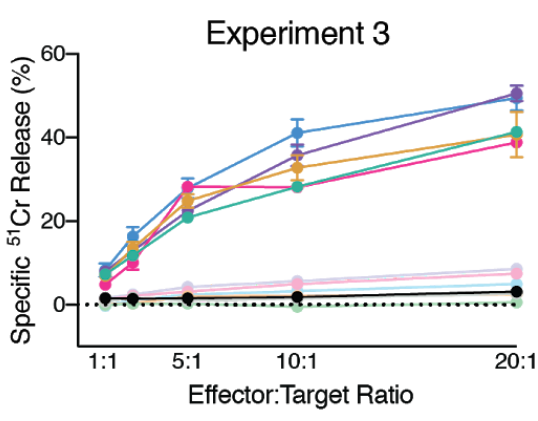

ProCAR-2 $\square$ ProCAR-3

Supplemental Data Figure 9: All murine CAR T-cell chromium killing assays. Four-hour ${ }^{51} \mathrm{Cr}$ release cytotoxicity assays were performed using fresh preparations of primary mouse proCAR T cells co-cultured with ${ }^{51} \mathrm{Cr}$ labelled MC57-HER2 tumour cells or MC57-Parental tumour cells. Three independent experiments with triplicate technical replicates for each effector:target ratio were performed. Empty vector used as non-HER2 targeted control. Data presented as mean \pm SEM. 
a

IFN- $\gamma$

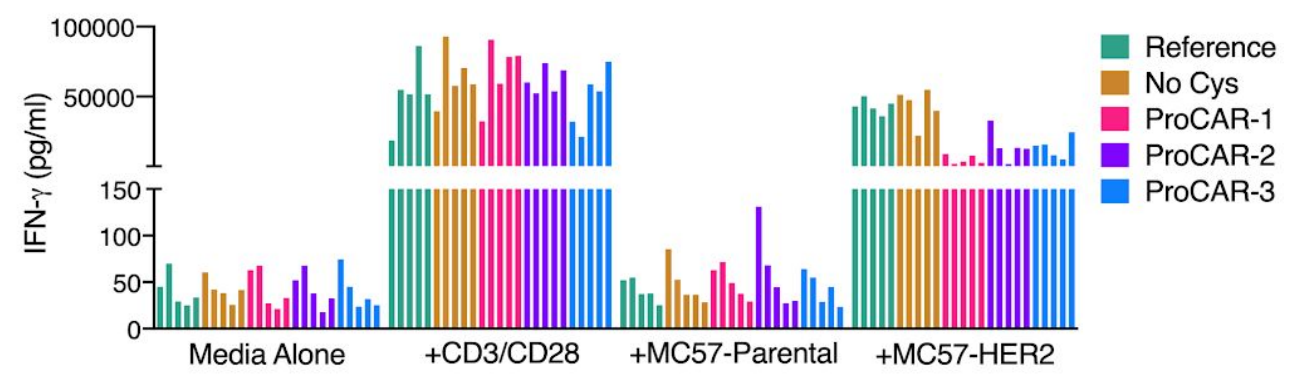

b

IL-2

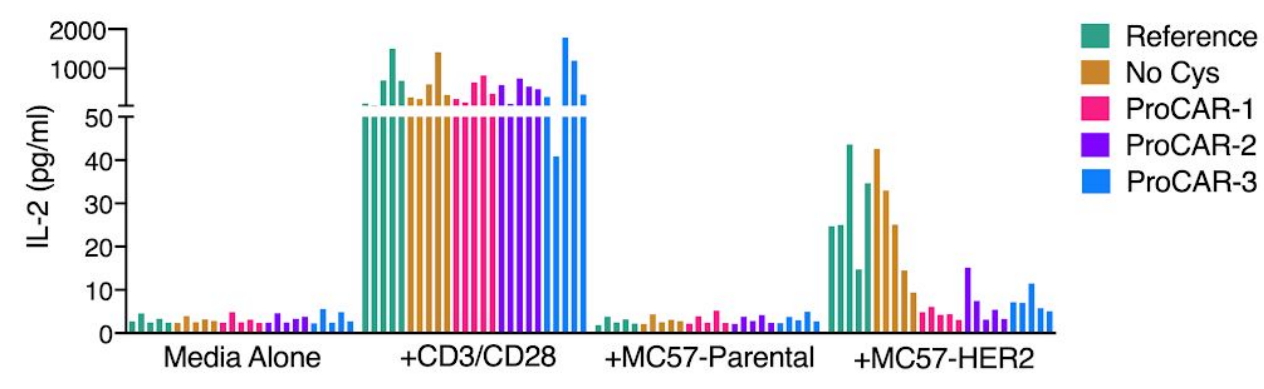

C

TNF $\alpha$

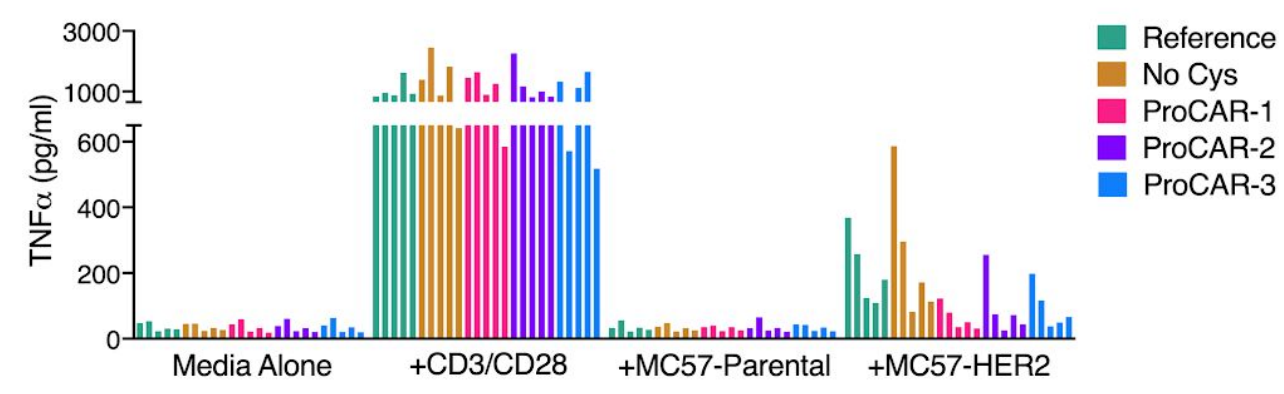

d

GM-CSF

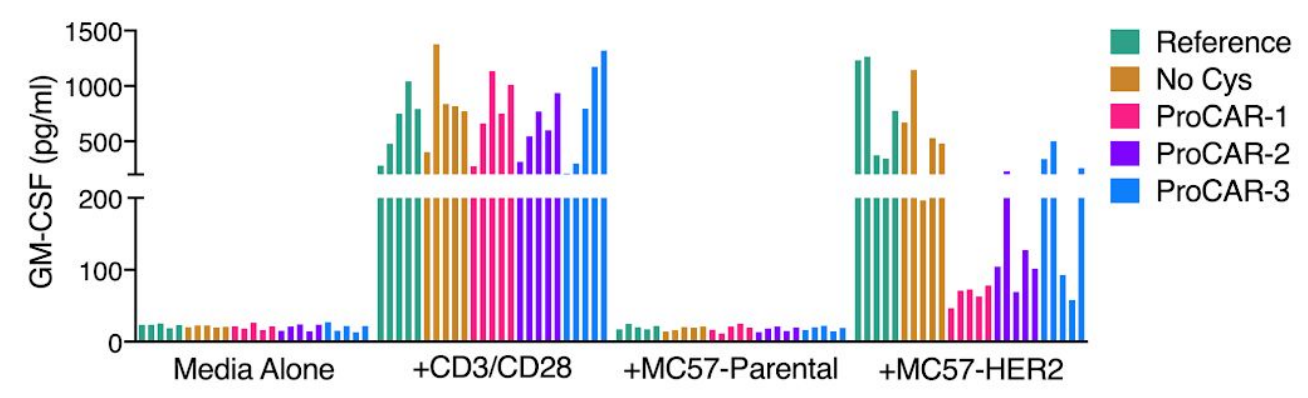

Supplemental Data Figure 10: All murine CAR T cell cytokine secretion assays. Murine CAR T cells were co-cultured with media alone, CD3/CD28 dynabeads, MC57-Parental tumour cells or MC57-HER2 tumour cells for 24 hours, and cell culture supernatants analysed using LEGENDPlex Cytokine kits for (a) IFN- $\gamma$, (b) IL-2, (c) TNFa and (d) GM-CSF. Each individual bar represents the mean of 3 technical replicates from one experiment, in order from experiment 1-5 (experiment 1-3 match experiment 1-3 from chromium killing assays). Cytokine secretion by reference, no cysteine, proCAR-1, proCAR-2 and proCAR-3 CAR T cells were assessed. 